\title{
Bi-specific Antibody Y111, Targeting PD-L1 and CD3 Considerably Enhances the Therapeutic Efficacy of Adoptive Transferred VY2Vס2 T Cells
}

\section{Rui Yang}

Wuhan YZY Biopharma Co.,Ltd

\section{Susu Shen}

Wuhan YZY Biopharma Co.,Ltd

Cheng Gong

Wuhan YZY Biopharma Co.,Ltd

Xin Wang

Wuhan YZY Biopharma Co.,Ltd

Fang Luo

Wuhan YZY Biopharma Co.,Ltd

Fengyan Luo

Wuhan YZY Biopharma Co.,Ltd

Yang Lei

Wuhan YZY Biopharma Co.,Ltd

Zili Wang

Wuhan YZY Biopharma Co.,Ltd

Shasha Xu

Wuhan YZY Biopharma Co.,Ltd

Qian Ni

Wuhan YZY Bioppharma Co.,Ltd

Yan Xue

Wuhan YZY Biopharma Co.,Ltd

Zhen Fu

Wuhan YZY Biopharma Co.,Ltd

Liang Zeng

Wuhan YZY Biopharma Co.,Ltd

Lijuan Fang

Wuhan YZY Biopharma Co.,Ltd

Yongxiang Yan

Wuhan YZY Biopharma Co.,Ltd

Jing Zhang 
Wuhan YZY Biopharma Co.,Ltd

\section{Lu Gan}

Huazhong University of Science and Technology - Main Campus: Huazhong University of Science and Technology

\section{Jizu Yi}

Wuhan YZY Biopharma Co.,Ltd

Pengfei Zhou ( $\nabla$ pfzhou@yzybio.com )

Wuhan YZY Biopharma Co.,Ltd

\section{Research}

Keywords: [CD3xPD-L1], Vy2Vס2 T cells, adoptive transfer, immunotherapy

Posted Date: December 15th, 2020

DOl: https://doi.org/10.21203/rs.3.rs-125326/v1

License: (c) (i) This work is licensed under a Creative Commons Attribution 4.0 International License. Read Full License 


\section{Abstract}

\section{Background:}

Anti-cancer immunotherapy based on the adoptive transfer of $\mathrm{V} Y 2 \mathrm{~V} \delta 2 \mathrm{~T}$ cells has benefited to some patients in clinical trials, but the overall responses are inconsistent. Therefore, new strategies are urgently needed to improve the current therapy.

\section{Methods:}

In this study, a designed bispecific antibody Y111, which binds to both CD3 and PD-L1, is applied to optimally potentiate Vy2Vס2 T cell-based killing of cancer cells. The binding activities of Y111 was determined by Flow cytometry. CFSE/PI-based flow cytometry was applied to check the re-directed killing ability induced by Y111 in the condition of using T cell subsets, or expanded- and purified- VY2Vס2 T cells as effector cells. Moreover, expanded-and purified- VY2Vס2 T cells were co-cultured with tumor cells in the presence/absence of $\mathrm{Y} 111$ to assess the activation, degranulation, and cytokine production by intracellular cytokine staining, and CBA method. Finally, NPG-based subcutaneous tumor mouse models were used to check the in vivo therapeutic efficacy of the combination of transfused Vy2Vס2 T cells and Y111.

\section{Results:}

Due to its binding activities, Y111 apparently prompts fresh a 3 -mediated lysis of tumor cell line H358 cells, but spare the effect on the fresh enriched VY2Vס2 T cells from the same donors. However, Y111 increases cytotoxicity of expanded and purified VY2Vס2 T cells against various NSCLC-derived tumor cell lines in a tumor cell dependent fashion. Y111 also prompted the releases of granzyme B, IFNY and TNFa. Supporting to these observations in vitro, a combination of adoptive transferring $\mathrm{V}_{\gamma} 2 \mathrm{~V} \delta 2 \mathrm{~T}$ cell and $\mathrm{Y} 111$ into the tumor-bearing NPG mice inhibited the growth of the established tumors in the mice.

\section{Conclusions:}

Taken together, our data suggest clinical potential for adoptive transferring the bispecific antibodyarmored Vy2Vס2 T cells to treat solid tumors, such as NSCLC.

\section{Background}

The Vy2Vס2 T cells, accounted for about $90 \%$ of total $ү \delta \mathrm{T}$ in healthy adults' peripheral blood, appear to be a fast-acting non-conventional T-cell population that contribute to both innate and adaptive immune responses against microbial infections and cancers [1]. Due to their unique biological features, Vy2Vס2 T cells have been widely used for adoptive cell immunotherapy in clinical trials to treat a broad range of cancers that display resistance to standard therapies [2]. However, the current VY2Vס2 T cells-based therapies have showed limited efficacy against solid tumors due to poor infiltration and impaired antitumor functions of transfused Vy2Vס2 T cells induced by tumor environment [3]. 
Various preclinical strategies are currently developed to enhance the therapeutic potential of novel optimized VY2Vס2 T cell-based immunotherapies targeting various pathways. Over three decades ago, Ferrini et al initially verified the concept that bispecific antibodies (bsAbs) targeting the $\gamma \delta$ TCR and a folate binding protein enhanced the cytotoxicity of $\gamma \delta$ T-cells to human ovarian carcinoma cells [4]. Several studies to exploit the synergic effects of the combination of a bispecific antibody with $\mathrm{V} Y 2 \mathrm{~V} \delta 2 \mathrm{~T}$ cells on fighting tumors were reported in recent years. The combination of designed bispecific antibodies targeting to Her2 and CD3 or Vy2 $[5,6]$, together with the transferred $V_{Y} 2 \mathrm{~V} \delta 2 \mathrm{~T}$ cells in presence of IL2, has achieved a significant delay in growth of pancreatic ductal adenocarcinoma tumor in murine model [7]. Another bispecific VHH construct, namely 7D12-5GS-6H4, targeting to epidermal growth factor

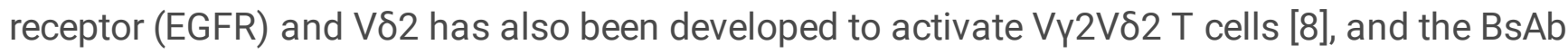
significantly prompted the survival time of xenograft bearing mice in the presence of transfused $V_{Y} 2 \mathrm{~V} \delta 2$ T cells pulsing the repeatedly injections of IL2 [9]. Moreover, a recent study demonstrated that the combination of checkpoint blockade and immune cell redirection could further enhance the anti-tumor effects of the adoptively transfused- and IL2 stimulated-VY2Vס2 T cells [10]. However, these mentioned bispecific antibodies are either originally from mice, which raised the risks including the occurrence of the immunogenicity and cytokine release syndrome, or in a form of VHH structure, which has a short half-life time in the blood [11]. Also, the TCR-based bispecific antibodies showed modest activities of tumor growth inhibitions with the co-administration of IL2, yet, this approach attracted less efforts than the exploring on CD3-targeting bsAbs [12].

Lung cancer is still the leading cause of cancer patients' deaths worldwide (https://canceratlas.cancer.org/the-burden/lung-cancer/). The clinical response rates of non-small cell lung cancer (NSCLC) patients, which accounts for approximately $85 \%$ of lung cancers, to the current first or second line treatment are still unsatisfying[13,14]. Although the adoptive transfer of $\mathrm{V} Y 2 \mathrm{~V} \delta 2 \mathrm{~T}$ cells could reduce the growth of lung cancer cell and prolong the survival of NSCLC-tumor bearing mice [15, 16], this immunotherapy has be proved to be safe but only effective in stabilizing the cancer progress in clinical trials during the past decades [17-19]. Also, the landscape-changing "Magacurve" for advanced NSCLC has shown the therapeutic successes of PD1/PD-L1 blockade [20], the monotherapy of receiving anti-PD1/PD-L1 agents results in response only in a small proportion of NSCLC patients [21]. Hence, to underline and illustrate a new strategy regarding the combination of the Vy2Vס2 T cells-based transfer therapy and PD-L1 targeting therapy, is to be explored for the treatment of NSCLC.

In this study, we designed a novel bispecific antibody Y111, targeting CD3 and PD-L1, on the format of patented Y-body ${ }^{\circledR}$. Our data showed that the binding affinity of $Y 111$ to PD-L1 was similar to that of Tecentriq, while Y111 displays reduced affinity to CD3 expressed on T cells, comparing to parental monoclonal antibody. As Y111 efficiently bridged T cells and tumor cells, it could selectively trigger the enhanced expressions of IFNY and TNFa, and up-regulate CD107a on VY2Vס2 T cells co-cultured with tumor cells. Furthermore, Y111 redirected the killing ability of VY2Vס2 T cells against various NSCLC cell lines at a 1:1 E: T ratio with the cytotoxicity ability $\left(\mathrm{EC}_{50}\right)$ at pM scale, through secretion of IFNy, TNFa, and Granzyme B. Finally, the combination of Y111 and transfused Vy2Vס2 T cells displayed therapeutic 
effects by delaying the growth of the established xenograft in immunodeficient NPG mice. Taken together, our data revealed a new strategy for developing more efficient $\mathrm{V} Y 2 \mathrm{~V} \delta 2 \mathrm{~T}$ cells-based immunotherapy, and this approach for NSCLC could be applied to other types of cancers with the advantages of the easy replacement of versatile tumor associated targets in the Y-body® platform and the potential anti-tumor nature of $\mathrm{V} Y 2 \mathrm{~V} \delta 2 \mathrm{~T}$ cells.

\section{Methods}

\section{Generation, production and purification of bispecific Antibody}

The Y111 is a recombinant anti-PD-L1 and anti-CD3 (PD-L1 1 CD3) bispecific antibody generated from $\mathrm{CHO}$ cell expression system. The anti-PD-L1 monovalent unit was from Tecentriq. The protein sequence of Tecentriq was obtained from the drug bank website (https://go.drugbank.com/drugs/DB11595), and then was reversely translated into the DNA sequence for synthesizing. The sequence encoding the antiCD3 single chain unit was reversely translated from the protein sequences of 2A5 (WO2020168555), a CD3 monoclonal antibody. These coding sequences were inserted into pEASY-T1 vector (Transgene, China) and verified by sequencing these vectors (Huada Gene, China). Then these expression cassettes were introduced into expression vectors respectively. The alternative control molecule, CD3 Isotype, targeting to CD3 and fluorescein (derived from Clone 4-4-20 [22]) was similarly prepared. Subsequently, these expression plasmids were transfected into $\mathrm{CHO}$ cells (Invitrogen) using the Fecto PRO Reagent (Ployplus, 116 - 010) according to the manufacturer's protocol. After 7-day culturing, the cell culture supernatant was collected and the serially purified by Sepharose Fast Flow protein A affinity chromatography column (GE), Fab Affinity KBP Agarose High Flow Resin (ACROBio systems), and SP cation exchanged chromatography column (GE). The purified proteins were analyzed by SDS-PAGE and coomassie blue staining.

\section{Cancer cell lines}

The four human NSCLC cell lines, NCl-H1975 (human adenocarcinoma epithelial cell line, CRL-5908) and $\mathrm{NCl}-\mathrm{H} 358$ (human lung bronchioalveolar carcinoma cell line, CRL-5807), A549 (human adenocarcinoma epithelial cell line, CRL-185), and NCl-H1299 (human NSCLC metastatic cell line, CRL-5803) were purchased from ATCC. Cells were cultured in RPMI 1640 medium (Gibco) supplemented with $10 \%$ FBS (Excell) except for A549, which was cultured in F-12K medium (Gibco) supplemented with 10\% FBS (Excell). Prior to use, the viability and density of cells were determined by Vi-Cell counter (Beckman Coulter). All cell lines in use were routinely tested for Mycoplasma infection using a 16 s-based PCR kit (Vazyme, Nanjing, China), and new cultures were established monthly from frozen stocks as described previously[23].

\section{Ex vivo expansion and purification of $\mathrm{VY} 2 \mathrm{~V} \delta 2 \mathrm{~T}$ cells in PBMC cultures}


The protocols for human blood samples for in vitro experimental procedures were evaluated and approved by the institutional review boards for human subjects' research and institutional biosafety committees at Huazhong University of Science and Technology (Wuhan, China). All subjects are adults who signed on the written informed consents.

This expansion protocol was performed as previously described [24]. Human peripheral blood mononuclear cells (PBMCs) were isolated from the fresh blood collected from random healthy adult donors (LDEBIO, Guangzhou) and purified by density gradient centrifugation using Ficoll-Hypaque PLUS (GE). These PBMCs were frozen in liquid nitrogen prior to use, as clinic trials evaluating the anti-cancer efficiency of the VY2Vס2 T cells usually utilized frozen PBMCs as starting cell population for further culture. After thawing quickly and counting cell numbers using AO/PI staining with Cellometer K2 Fluorescent Cell Viability Counter (Nexcelom Bioscience), PBMCs were cultured in RPMI 1640 medium (Gibco) supplemented with 10\% FBS (Excell), $2.5 \mu \mathrm{M}$ Zoledronic Acid (Sigma Aldrich), and $1000 \mathrm{IU} / \mathrm{mL}$ IL2 (Sihuan Pharm, Beijing) at $2 \times 10^{6} \mathrm{cells} / \mathrm{mL}$ seeded in 6-well-plate. Every 3 days, half volume of the culture media was removed and replaced with fresh culture media containing $1000 \mathrm{IU} / \mathrm{mLIL} 2$. Depending on the media color and cell density, cultured cells were pooled and transferred into T75 flasks. During days $12-14$, VY2V $22 T$ cells were purified by negative selection from these cultures using the Miltenyi TCR $\gamma / \delta+T$ Cell Isolation Kit (130-092-892). Cell purity was $>96 \%$ assessed by flow cytometry, and these cells were cultured in RPMI 1640 medium (Gibco) supplemented with 10\% FBS (Excell) overnight for rest. Then, these cells were used for either killing and functional assays in vitro or assessing anti-tumor activity in vivo (Sup. Figure 1)

\section{Cell binding and co-binding assay}

To determine the affinity of Y111 at its anti-CD3 and anti-PD-L1 moieties to T cells and tumor cells, a flow cytometry-based method was applied to measure the cell binding activities of Y111 as described in a previous reprot [25]. T cells or tumor cells were incubated in the presence of serially diluted antibodies for 1 hour at room temperature. Subsequently, the cells were washed twice in FACS buffer (PBS + 2\%FBS + 2 mM EDTA) and stained with PE-conjugated anti-human IgG Fc antibody (Clone HP6017, Biolegend) diluted in 1:100 into FACS buffer for 25 minutes. Bound antibodies were detected using flow cytometry.

To determine the cell-to-cell association mediated by Y111, CFSE-stained H1975 cells were co-cultured with PKH26-labelled Jurkat cells at a ratio of 1:1 with range concentrations of the Y111 or CD3 Isotype for 1 hour in a 96-well-plate. Samples were measured by flow cytometry on a FACSelesta instrument (BD) and analyzed with FlowJo software (BD). Co-binding\% of two cells was indicated as the percentages of the $\mathrm{CFSE}^{+} \mathrm{PKH} 26^{+}$double positive cells among the total cells.

\section{In vitro tumor cell killing assay}

All tumor cell lines were cultured and maintained in T75 flasks prior to use. These cell lines were selected as target cells for the cytotoxicity assay due to their high expression levels of PD-L1 (Sup. Figure 4). On the first day of the cytotoxicity assay, $2 \times 10^{4}$ CFSE-labelled target cells were seeded and co-cultured with 
the enriched-and expanded- $\mathrm{V} Y 2 \mathrm{~V} \delta 2 \mathrm{~T}$ cells at a 1:1 ratio, or with the purified $\mathrm{T}$ cell subsets from fresh PBMC at 1:10 ratios (using the respective negative isolation kits (Miltenyi Biotech) according to the manufacturer's instructions, and Sup. Figure 6), with a various doses of indicated antibodies. The cells were incubated at $37^{\circ} \mathrm{C}$ for $12 \mathrm{~h}$ in a humidified $\mathrm{CO}_{2}$ incubator. Flow cytometry was used to determine antibody-induced cytotoxic activity-mediated by $\mathrm{V} \gamma 2 \mathrm{~V} \delta 2 \mathrm{~T}$ cells as described previously [25]. The percentages of $\mathrm{CFSE}^{+} \mathrm{PI}^{+}$cells among the total of target cells $\left(\mathrm{CFSE}^{+}\right)$were defined as "Cytotoxicity \%".

\section{Intracellular cytokine staining (ICS) for T cell activation evaluation}

Flow cytometry was performed as described in the other reports[26, 27]. 0.1 Million H1975 cells was firstly plated in 24-well-plate. On the next day, 0.25 million expanded and negatively enriched VY2Vס2 T cells were added into the wells with doses of Y111 or CD3 Isotype with BV510-anti-CD107a (H4A3, Biolegend) and BFA (Golgi Plug, BD). After co-cultured for 6 hours, the cells were stained with Zombie Fixable Viability Kit (Biolegend), incubated with APC-anti-CD3 (SP34-2, BD), PE-anti-V82 (B6, Biolegend) for $20 \mathrm{~min}$ at room temperature in dark. Cells were permeabilized for $30 \mathrm{~min}$ at 4 degrees (Cytofix/Cytoperm, BD). After wash, cells were incubated with BV650-anti-IFNy (4S.B3; Biolegend), BV421anti-TNFa (Mab11, Biolegend) for $30 \mathrm{~min}$ at room temperature in dark. Then cells were washed and analyzed by a BD FACSelesta flow cytometry. Flow data was analyzed by FlowJo (BD).

\section{CBA for measuring released cytokines}

The supernatant was collected from $\mathrm{T}$ cell and tumor cell co-culture system before adding propidium iodide (PI) for measuring cytotoxicity, and stored at -80 degree until measurement. The human IFNy (560111, BD), TNFa (560112, BD) and Granzyme B (560304, BD) Flex Set kit were used for determining the concentrations of these cytokines by the cytometric bead array (CBA) method according to manufacturer's instructions. In order to display the increased production of cytokines induced by the antibodies, raw values were subtracted from the values of $E+T$ groups.

\section{Mice tumor generation and treatment with purified Vy2Vס2 T cells pulse Y111}

All handing and care procedures of animal were performed in accordance to guidelines issued from the relevant Ethics Committee. The animal study protocols were approved by the Institutional Animal Care and Use Committee at Huazhong University of Science and Technology (Wuhan, China).

Female NOD.Cg-Prkdc ${ }^{\text {scid }}$ IL2rg ${ }^{\text {tm1Vst }} /$ Vst (NPG) mice were obtained from the VITALSTAR (Beijing, China) at age of 6-8 weeks and housed in the central laboratory in Hubei Province Food and Drug Safety Evaluation Center. 5 million H1975 cells were injected s.c. into NPG mice for tumor xenotransplantation on Day 0. Until to Day 15 post tumor cell inoculation, tumor volumes had reached to about $220 \mathrm{~mm}^{3}$, mice were randomly divided into four groups ( $n=7$ per group) (Sup. Figure $6 \mathrm{~A}$ ). On Day 17, mice were injected i.v. with 1 million purified $V_{Y} 2 \mathrm{~V} \delta 2 \mathrm{~T}$ cells with/without $1 \mathrm{mg} / \mathrm{kg}$ or $4 \mathrm{mg} / \mathrm{kg} Y 111$. This treatment 
was followed on Days 20, 24 and 27 (twice a week for 2 weeks). Mice treated with PBS were used as negative control. For each treatment, purified $\mathrm{V}_{Y} 2 \mathrm{~V} \delta 2 \mathrm{~T}$ cells were negatively enriched from frozen PBMC from the same donor treated with $2.5 \mathrm{uM} \mathrm{Zol}+1000 \mathrm{IU} / \mathrm{mL} \mathrm{IL} 2$ for 10-14 days. Tumor volumes were measured with a digital caliper three times a week and calculated using the formula: Tumor Volume $\left(\mathrm{mm}^{3}\right)=\left(a \times b^{2}\right) / 2$, where $a$ is the longitudinal length and $b$ is the transverse width.

\section{IHC analysis}

To assess the infiltration and accumulation of transferred Vy2Vס2 T cells in vivo, mice were sacrificed at the end of the study. The tumor tissues were immediately removed, and cut into small pieces embedded in $4 \%$ paraformaldehyde for fixation. Then these tumor pieces were sectioned and examined by IHC staining using a rabbit-anti-human CD3 antibody (Clone SP7). Positive cells were counted in five random selected microscopic fields (magnification 20X) and supplied for further quantification analysis.

\section{Statistical analysis}

Statistical analyses were performed with Prism 6.0 (GraphPad software). Non-linear regression methods were used to analyze data derived from cell binding, co-binding, activation, and killing assays to plot Dose-Response curves. $P$ values were assessed by student's t-test, nonparametric Mann-Whitney U test, and one-way or two-way ANOVA, followed by Dunnett test or Tukey multiple comparison as appropriate. $P$ values $<0.05$ was considered significant.

\section{Results}

\section{Design and Generation of Y111 based on patented Y-body® platform}

Y111 (PD-L1 x CD3), aCD3-targeting bispecific antibody, that redirected T cells to attack PD-L1-expressing cancer cells, was designed with the Y-body ${ }^{\circledR}$ format in structure[25, 28]. Y111 consisted of a Fab structure targeting PD-L1 derived from Tecentriq (Atezolizumab), a single chain variable fragment (scFv) for activating CD3 originated from a monoclonal antibody 2A5 (WO2020168555), and a modified Fc region (Fig. 1A). The Fc region of Y111 is emanated from human IgG1, but engineered with "Knob-intoHole" mutations for favorable formation of the heterodimer, and with deficiency in ADCC activity as previously described [25]. The purity and molecular weight of Y111 was verified by size-exclusion chromatograms SEC and SDS-PAGE. As expected, under reducing conditions the bands in the gel demonstrated the three chains of $\mathrm{Y} 111$, i.e. heavy chain $(\mathrm{Y} 111 \mathrm{H})$, light chain $(\mathrm{Y} 111 \mathrm{~L})$, and single chain $(\mathrm{scFv})$, while a monoclonal antibody displayed two bands consisting of the heavy $(\mathrm{NH})$ and light $(\mathrm{NL})$ chains derived from Nivolumab (Fig. 1B). Moreover, the SEC analysis indicated that the purity of this Y111 sample was more than 99\% (Fig. 1C).

\section{Binding properties of Y111}


The cell binding activity of $\mathrm{Y} 111$ was measured using flow cytometry. We initially assessed the affinity of Y111 at the anti-CD3 moiety on Jurkat cells. It was not surprising to find that the affinity of Y111 was 360-folds weaker than that of 2A5 (the parental CD3-targeting mAb of Y111) to Jurkat cells, as the dissociation constants $(\mathrm{Kd})$ for $\mathrm{Y} 111$ and $2 \mathrm{~A} 5$ to Jurkat were $711.4 \mathrm{nM}$ and $1.96 \mathrm{nM}$, respectively (Fig. 2A), which were consistent with previous reports [11, 25]. Then, $\mathrm{H} 1975$ cells were chosen for measuring the binding affinity of the anti-PD-L1 moiety of Y111 to PD-L1. The Kd for Y111 binding to $\mathrm{H} 1975$ was $0.84 \mathrm{nM}$, and the $\mathrm{Kd}$ of Tecentriq binding to the cell was $0.21 \mathrm{nM}$ (Fig. 2B). The cell affinity of Y111 was equivalent to that of Tecentriq, as both had the same variable regions of anti-PD-L1.

Bispecific antibody mediating $T$ cells recruitment to cancer cells is thought to be a critical working mechanism [11]. We therefore investigate whether $\mathrm{Y} 111$ could induce the formation of an in-tans bridge between $T$ cells and tumors cells through its dual binding functions. To this end, Jurkat cells stained with CFSE were incubated with $\mathrm{H} 1975$ cells labelled with $\mathrm{PKH} 26$ for 1 hour, then the proportion value of double positive cells was measured to represent the bridging activity of Y111[25]. In the presence of CD3 Isotype at $10 \mu \mathrm{g} / \mathrm{mL}$, the double positive cell population was $1.79 \%$ (Fig. 2C). Y111 at the concentration of $10 \mu \mathrm{g} / \mathrm{mL}$ significantly induced the formation of bridge between T cells and tumor cells as indicated by the increased up to $34.6 \%$ of double positive population, (Fig. 2C). Interestingly, while Y111 displayed a dose-dependent manner in enhancing the levels of cell-to-cell association $\left(\mathrm{EC}_{50}=72.1 \mathrm{pM}\right), \mathrm{CD} 3$ Isotype control was unable to increase the levels of cell-to-cell association (Fig. 2D). Taken together, these data demonstrated the unique binding activities of Y111 by the anti-PD-L1 moiety to the tumor cells and by the anti-CD3 moiety to the T cells.

\section{Y111 induced activation of Vy2Vס2 T cells was selectively depended on the presence of tumor cells}

Vy2Vס2 T cells exerted direct killing the tumor cells through the releasing of cytokines, such as IFNY and TNFa, and cytotoxicity [2]. We then sought to investigate the effect of $\mathrm{Y} 111$ on the activation of Vy2Vס2 T cells to determine whether the Y111-midated activation was depended on the presence of a tumor cell. To this end, the purified Vy2Vס2 T cells (the purity and quality of Vy2Vס2 T cells was shown in Sup. Figure 1) were cultured with/without $\mathrm{H} 1975$ cells under a serial diluted concentration of the Y111antibody for 6 hours. Then, we measured the cell surface expression of CD107a to assess the degranulation of cytotoxic molecules for killing activity of the Y111[24, 29], and the intracellular expression of IFNY and TNFa for evaluating its anti-tumor effector function [30]. With the stimulation of both Y111 and tumor cells, a higher proportion of $V_{Y} 2 \mathrm{~V} \delta 2 \mathrm{~T}$ cells displayed potent effector function and degranulation at $1 \mu \mathrm{g} / \mathrm{mL}$, which was not the case when the addition of CD3 Isotype instead of Y111 was used (Fig. 3A, Sup. Figure 2). Furthermore, the considerably unregulated expression of TNFa, IFNY, and CD107a was aborted in the absence of tumor cells even under the stimulation by Y111 (Fig. 3A). These data indicated that the activation of VY2Vס2 T cells was controlled jointly by both Y111 and tumor cells. Moreover, this specific activation was in a Y111 dose-depended manner (Fig. 3B). Multifunctional VY2V反2 T cells have been reported playing central roles in controlling the intracellular bacterial infection and killing transformed 
tumor cells [1, 31]. Indeed, we found the co-stimulation of $\mathrm{Y} 111$ and $\mathrm{H} 1975$ cells induced larger percentages of effector cells to produce three- and two- cytokines simultaneously (Fig. 3C). At last, we also observed a dose-depended increase of these multifunctional VY2Vס2 T cells after co-incubation of both the Y111 and tumor cells (Sup. Figure 3). Taken together, these data demonstrated that the efficiently activation of $\mathrm{V} Y 2 \mathrm{~V} \delta 2 \mathrm{~T}$ cells was depended on the simultaneous binding of the $\mathrm{Y} 111$ to both VY2Vס2 T cells and PD-L1 positive tumor cells.

\section{The killing various PD-L1-positive NSCLC cell lines by VY2Vס2 T cells was significantly increased by Y111}

As the crosslinking of PD-L1 on the target cells with CD3 on the T cells mediated by the bispecific antibody was expected to cause effector T-cell-dependent lysis of target cells [11], we then checked whether Y111 could redirect VY2V82 T cells to kill PD-L1 positive tumor cells. Although the expression levels of PD-L1 was used as a favorable predictive biomarker, approximately only $20-30 \%$ NSCLC patients responded to the current PD1/PD-L1 blocking therapy [32]. Thus, we initially chose four NSCLC cell lines including A549, H1299, H1975 and H358 in this proof-of-concept study. These four types of cancer cells exhibiting in PD-L1 high expression demonstrated by flow cytometry, were used for the investigation of cytotoxicity of VY2Vס2 T cells mediated by Y111 in vitro (Sup. Figure 4). When CFSEstained tumor cells were co-cultured with purified $\mathrm{V}_{Y} 2 \mathrm{~V} \delta 2 \mathrm{~T}$ cells at a ratio of 1:1 with a range of serial diluted antibodies for 12 hours, tumor cells were killed efficiently in a dose-dependent manner of Y111, but this was not the case for CD3 Isotype or Tecentriq at any tested concentrations (Fig. 4). As Y111 alone did not alter the viability of tumor cells (Sup. Figure 5), it was believed that the observed high cytotoxicity was directly elicited by Y111. Although the anti-PD-L1 activity of Y111 may block the PD1/PD-L1 interaction and act as a checkpoint blockade, we could not find the increase of cytotoxicity in Tecentriq group (Fig. 4).

We further tested whether Y111 redirected fresh VY2Vס2 T cells to kill PD-L1 positive tumor cells. Three T cell subsets, including CD4+, CD8+, V82 T cells, were negatively isolated from the same donor, and cocultured with $\mathrm{H} 358$ cells in a ratio of 10:1 (E: $\mathrm{T}$ ) in the presence of diluted Y111. Indeed, we could not

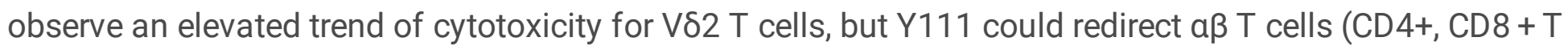
cells) to lyse H358 cells in a in a dose-dependent fashion (Sup. Figure 6A-B). In contrast, when H358 cells were co-cultured with established VY2Vס2 T cells purified from the same donor's PBMC treated with Zol + IL2 for 14 days in the presence of various antibodies (Y111, CD3 Isotype, and Tecentriq), serial diluted Y111 enhanced the cytotoxicity of VY2Vס2 T cells, whereas CD3 Isotype and Tecentriq did not (Sup. Figure 6C). This spurious finding was consistent with a previous study using a bispecific antibody targeting Her2 and CD3 [33]. The observed induced cytotoxicity ability of Y111 was PD-L1 dependent, as Y111 plus VY2Vס2 T cells had no effect on normal cells, such as PBMC from unrelated donors (Sup.

Figure 7). Taken together, these results demonstrated that Y111 could redirect VY2Vס2 T cells to kill PDL1 positive tumor cells, bust spared this ability to fresh Vס2 T cells. 


\section{The secretion of IFNy, TNFa, and granzyme B from VY2Vס2 T cells was enhanced by Y111 during killing}

The killing ability of VY2Vס2 T cells induced by Y111 prompted us to check the induced production of anti-tumor cytokines, including IFNy and TNFa, and cytotoxic mediator granzyme B in the above coculture system. We found $Y 111$, but not CD3 Isotype or Tecentriq, could significantly prompted the secretion of IFNY, TNFa, and granzyme B from VY2Vס2 T cells in the presence of tumor cells (Fig. 5A). Moreover, the evaluated production of IFNy and TNFa, and cytotoxicity mediator was consistent with the enhanced killing ability of $\mathrm{V} Y 2 \mathrm{~V} \delta 2 \mathrm{~T}$ cells mediated by $\mathrm{Y} 111$, as inferred from the significantly correlation coefficients between the induced secretion of IFNY, TNFa, and granzyme B and the cytotoxicity rates (Fig. 5B). However, no obvious increase of IFNY and TNFa in the co-culture of Y111 to redirect VY2Vס2 T cells to kill the unrelated PBMCs was observed (Sup. Figure 7).

\section{Adoptive transfer of purified- and expanded- Vy2Vס2 T cells with bispecific antibody Y111 displayed potent anti-tumor efficacy in NPG mice}

To assess the therapeutic potential of transfusing VY2Vס2 T cells with bispecific antibody Y111, we utilized H1975-NPG model to check whether this combination treatment could fight against advanced tumors in vivo (Fig. 6A). Tumors in experiments were allowed to grow for the formation of large established xenograft (about $230 \mathrm{~mm}^{3}$ ). As the cell expansion methodologies are not optimal at present for preparation of large-scale and clinic-grade Vy2Vס2 T cells used for clinic tumor therapy [34], and high numbers and repetitive administration of human VY2Vס2 T cells with phosphoantiens and IL2 are required to get optimal results in murine model [35]. We expected that using a relatively small amount of VY2Vס2 T cells for transfer without IL2 or aminobisphoshponates would generate a treatment widow to assess the synergic effects of combination of $\mathrm{V} Y 2 \mathrm{~V} \delta 2 \mathrm{~T}$ cells and $\mathrm{Y} 111$. In fact, adoptive transfer of purified- and expanded- Vy2Vס2 T cells alone had no effects in preventing the growth of established H1975-derived xenograft, compared to the control group (Fig. 6B-C). In contrast, the supplementation of Y111 with Vy2Vס2 T cells purified from the same donor significantly delayed the malignant progression, comparing to the control or the T cells alone groups (Fig. 6B-C). This significant inhibition effects of tumor growth started at Day 27 after tumor cell inoculation in the mice received both Vy2Vס2 T cells and $4 \mathrm{mg} / \mathrm{kg}$ Y111 (Fig. 6B, Sup. Figure 8A). Moreover, this $4 \mathrm{mg} / \mathrm{kg} \mathrm{Y111} \mathrm{elicited} \mathrm{superior} \mathrm{therapeutic} \mathrm{effects}$ than $1 \mathrm{mg} / \mathrm{kg} Y 111$, with a greater extend of delaying tumor growth of this group than other groups (Fig. 6B-C). Ultimately, the observed inhibitory effects were associated with significant increases in the infiltration and accumulation of transfused VY2Vס2 T cells T cells induced by Y111 (Fig. 6D-E). During the study, the Y111 treatment resulted in no or little weight loss in mice, suggesting potential safety to clinical applications (Sup. Figure 8B). Taken together, these data demonstrated that Y111 could further enhance the anti-tumor efficacy of transfused Vy2Vס2 T cells. 


\section{Discussion}

Since the discovery of Vy2Vס2 T cells in the late 1980s, a significant amount of knowledge has been accumulated concerning its vital roles in killing tumor cells and controlling tumor growth, raising the possibility of its therapeutic application for anti-cancers[31, 36, 37]. However, the results of various completed clinical trials using transferred $\mathrm{V}_{\mathrm{Y} 2 \mathrm{~V} \delta 2} \mathrm{~T}$ cells against both hematological malignancies and solid tumors were proved to be ineffective with only a few complete response [31, 38]. This consistentlacked results are related to the failure of transfused $\mathrm{V} Y 2 \mathrm{~V} \delta 2 \mathrm{~T}$ cells into tumor sites and suppressive tumor environment $[3,39]$. Thus, we redirected the transfused Vy2Vס2 T cell to tumor sites to kill PD-L1 positive tumor cells by its combination with a CD3 and PD-L1 targeting bsAb, which prompted the its infiltration and persistence in tumor sites. This proof-of-concept study also verified the value of bsAbbased immunotherapeutic approach to leverage the potent anti-tumor capacity of VY2Vס2 T cells, and suggested that this combination strategy could be used to other types of cancer.

With the obligatory ability in binding two specificities simultaneously, bispecific antibodies are progressing into clinical developments for a wide variety of tumors $[11,28]$. In this study we generated an anti-PD-L1 X anti-CD3 bsAb Y111, based on Y-body® technological platform, which was characterized as an asymmetric format for easily purification, with the modified $\mathrm{Fc}$ fragment to abolish Fc-mediated effector functions $[25,28]$. The observed MW of $\mathrm{Y} 111$ was larger than theoretical MW, as a result of the Nlinked glycosylation, which prompted its stability [25]. Moreover, Y111 retained relatively weaker binding affinity to CD3 molecule, comparing to its parent monoclonal antibody $2 A 5$, but displayed a similar affinity to PD-L1 as that of Tecentriq. The reduced affinity for CD3 of Y111 (711.4 nM) was desired for clinical applications since several studies had shown that a lower affinity of the anti-CD3 moiety of bsAbs contributes to the efficient tumor infiltration of T cells without rapid CD3-modulated plasma clearance [40-42], in addition of mitigating cytokine release syndrome (CRS) [25, 28]. Indeed, our data indicated that $Y 111$ could prompt $T$ cell infiltration into tumor sites in vivo, while it still induces highly potential cytotoxicity against tumor cells in vitro.

This different susceptibility of fresh $a \beta$, fresh and expanded $\gamma \delta T$ cells-modulated killing of tumor cells induced by Y111 may be attributed to the various action mechanisms of TCR activation by these cells reported by several reports $[24,43,44]$. As bsAbs were expected to recruit and re-direct T cells into tumor sites directly from blood, the above finding indicated that this immunotherapy would miss out the power of Vy2Vס2 T cells. We therefore believed that the potential anti-tumor expanded Vy2Vס2 T cells would benefit to improve current therapy taking advantages of bsAbs. Indeed, our data demonstrated Y111 triggered strong expression of CD107a on the surfaces of VY2Vס2 T cells in the presence of tumor cells, and selectively provoked the production of IFNY and TNFa. However, the Y111-induced cytotoxicity of Vy2V82 T cells was abolished when normal cells, such as PBMC, were used for target, suggesting that the safety profiles remained even under the condition of combining Vy2Vס2 T cells with CD3-targeting bsAbs [10,33]. Moreover, the observed killing of PD-L1-expressed NSCLC cell lines was not affected by gene mutation status in these cell lines, such as the mutation of KRAS (A549 and H358), of EGFR 
(H1975), and the loss of P53 (H358 and H1299). This gene mutation-ignored killing mechanism of our approach further proved the potential anti-tumor nature exhibited by Vy2Vס2 $T$ cells $[31,36,45]$.

While expanding a large scale of autologous $\mathrm{V} Y 2 \mathrm{~V} \delta 2 \mathrm{~T}$ cells from cancer patients ex vivo still represents a major clinical challenge [37], we explored the antitumor activity of allogeneic Vү2Vס2 T cells in NPG mice bearing tumor cell line derived xenograft. Our approach seems particularly promising given the potential of controlling the growth of established tumors, while a single arm therapy of transfused Vy2V82 T cells alone was not effective. This better tumor control was consistent with the increased cytotoxicity of this treatment in vitro. Due to the limitation of immunodeficiency NPG mice used in this study, we could not test whether our strategy exert direct remittance to the suppressive tumor microenvironment. However, we found Y111 could increase the trafficking of transferred Vy2Vס2 T cells to the tumor site, which provided the proof of the concept for the efficiency of this combination therapy. Above all, comparing to other studies using various bispecific antibody with VY2Vס2 T cells, our strategy provided effective and safety results even omitting the administration of IL2 with aminobisphoshponates or pyrophosphates for sensitizing tumor cells, or with other monoclonal antibody [10, 31].

\section{Conclusions}

In conclusion, our study demonstrates that bispecific antibody Y111, targeting CD3 and PD-L1, could harness the anti-tumor potential of Vy2Vס2 T cells to kill cancer cell lines in vitro and inhibit the growth of the established xenograft tumors in vivo. The current study provides new evidence to support the hypothesis that a CD3-targeting bispecific antibody has the potential to improve VY2Vס2 T cells-based anti-tumor efficacy, and this novel immunotherapeutic approach need further clinical exploration for potential benefit to cancer patients.

\section{Abbreviations}

ADCC: antibody-dependent cell-mediated cytotoxicity;

ATCC: American Type Culture Collection;

BsAb: bispecific antibody;

CBA, cytometric bead array;

CFSE: Carboxyfluorescein succinimidyl ester;

EGFR:epidermal growth factor receptor;

Fab: antigen-binding fragment;

ICS: Intracellular cytokine staining; 
IHC: Immunohistochemistry;

IFNY: Interferon Gamma;

NPG: NOD.Cg-Prkdc ${ }^{\text {scid }}$ IL2 $\mathrm{rg}^{\text {tm1Vst}} /$ Vst

NSCLC: non-small cell lung cancer

PBMCs: Peripheral blood mononuclear cells

PD1: Programmed cell death protein 1;

PD-L1: Programmed death-ligand 1;

Pl: propidium iodide

TNFa: Tumor necrosis factor alpha

SDS-PAGE: Sodium dodecyl sulfate-polyacrylamide gel electrophoresis

scFv: single chain variable fragment.

\section{Declarations}

\section{Ethics approval and consent to participate}

The protocols for human blood samples for in vitro experimental procedures were evaluated and approved by the institutional review boards for human subjects' research and institutional biosafety committees at Huazhong University of Science and Technology (Wuhan, China). All subjects are adults and signed written informed consents.

All handing and care procedures of animal were performed in accordance to guidelines issued from the relevant Ethics Committee. The animal study protocols were approved by the Institutional Animal Care and Use Committee at Huazhong University of Science and Technology (Wuhan, China).

\section{Consent for publication}

All authors read and approved the manuscript for publication.

\section{Availability of data and materials}

The datasets used and/or analyzed during the current study are available from the corresponding author on reasonable request. 


\section{Competing interests}

L.G declares no financial conflicts of interest. Others in the authorship are employees of Wuhan YZY Biopharma Co., Ltd.

\section{Funding}

This work was supported by National Natural Science Foundation of China (Grant No. 81901607).

\section{Author Contribution}

R.Y, G.L, J.Z.Y, and P.F.Z designed the project. Z.J, Y.X.Y, L.J. F and L.Z supervised the project. R.Y, S.S.S, Z.F, Y.X, C.G, X.W, F.L, Z.L.W, L.Y, and F.Y.L performed the experiments. R.Y, G.L, J.Z.Y and P.F.Z analyzed the data and jointly wrote the manuscript.

\section{References}

1. Shen, L., et al., Fast-acting gammadelta T-cell subpopulation and protective immunity against infections. Immunol Rev, 2020.

2. Beetz, S., et al., Human gamma delta T cells: candidates for the development of immunotherapeutic strategies. Immunol Res, 2007. 37(2): p. 97-111.

3. Lo Presti, E., et al., gammadelta T Cells and Tumor Microenvironment: From Immunosurveillance to Tumor Evasion. Front Immunol, 2018. 9: p. 1395.

4. Ferrini, S., et al., Re-targeting of human lymphocytes expressing the T-cell receptor gamma/delta to ovarian carcinoma cells by the use of bispecific monoclonal antibodies. Int J Cancer, 1989. 44(2): p. 245-50.

5. Oberg, H.H., et al., gammadelta T cell activation by bispecific antibodies. Cell Immunol, 2015. 296(1): p. 41-9.

6. Oberg, H.H., et al., Novel bispecific antibodies increase gammadelta T-cell cytotoxicity against pancreatic cancer cells. Cancer Res, 2014. 74(5): p. 1349-60.

7. Oberg, H.H., et al., Tribody [(HER2)2xCD16] Is More Effective Than Trastuzumab in Enhancing gammadelta T Cell and Natural Killer Cell Cytotoxicity Against HER2-Expressing Cancer Cells. Front Immunol, 2018. 9: p. 814.

8. de Bruin, R.C.G., et al., Highly specific and potently activating Vgamma9Vdelta2-T cell specific nanobodies for diagnostic and therapeutic applications. Clin Immunol, 2016. 169: p. 128-138.

9. de Bruin, R.C.G., et al., A bispecific nanobody approach to leverage the potent and widely applicable tumor cytolytic capacity of Vgamma9Vdelta2-T cells. Oncoimmunology, 2017. 7(1): p. e1375641. 
10. Guo, Q., et al., TIM-3 blockade combined with bispecific antibody MT110 enhances the anti-tumor effect of gammadelta T cells. Cancer Immunol Immunother, 2020.

11. Labrijn, A.F., et al., Bispecific antibodies: a mechanistic review of the pipeline. Nat Rev Drug Discov, 2019. 18(8): p. 585-608.

12. Ellerman, D., Bispecific T-cell engagers: Towards understanding variables influencing the in vitro potency and tumor selectivity and their modulation to enhance their efficacy and safety. Methods, 2019. 154: p. 102-117.

13. Garon, E.B., et al., Ramucirumab plus docetaxel versus placebo plus docetaxel for second-line treatment of stage IV non-small-cell lung cancer after disease progression on platinum-based therapy (REVEL): a multicentre, double-blind, randomised phase 3 trial. Lancet, 2014. 384(9944): p. 665-73.

14. Masters, G.A., et al., Systemic Therapy for Stage IV Non-Small-Cell Lung Cancer: American Society of Clinical Oncology Clinical Practice Guideline Update. J Clin Oncol, 2015. 33(30): p. 3488-515.

15. Dokouhaki, P., et al., Adoptive immunotherapy of cancer using ex vivo expanded human gammadelta $T$ cells: A new approach. Cancer Lett, 2010. 297(1): p. 126-36.

16. Kang, N., et al., Adoptive immunotherapy of lung cancer with immobilized anti-TCRgammadelta antibody-expanded human gammadelta T-cells in peripheral blood. Cancer Biol Ther, 2009. 8(16): p. $1540-9$.

17. Kakimi, K., et al., Adoptive transfer of zoledronate-expanded autologous Vgamma9Vdelta2 T-cells in patients with treatment-refractory non-small-cell lung cancer: a multicenter, open-label, single-arm, phase 2 study. J Immunother Cancer, 2020. 8(2).

18. Sakamoto, M., et al., Adoptive immunotherapy for advanced non-small cell lung cancer using zoledronate-expanded gammadelta Tcells: a phase I clinical study. J Immunother, 2011. 34(2): p. 20211.

19. Nakajima, J., et al., A phase I study of adoptive immunotherapy for recurrent non-small-cell lung cancer patients with autologous gammadelta T cells. Eur J Cardiothorac Surg, 2010. 37(5): p. 11917.

20. Brahmer, J., et al., Abstract CT195: Long-term survival outcomes with nivolumab (NIVO) in pts with previously treated advanced non-small cell lung cancer (NSCLC): Impact of early disease control and response. Cancer Research, 2019. 79(13 Supplement): p. СT195-CT195.

21. Sui, H., et al., Anti-PD-1/PD-L1 Therapy for Non-Small-Cell Lung Cancer: Toward Personalized Medicine and Combination Strategies. J Immunol Res, 2018. 2018: p. 6984948.

22. Kranz, D.M. and E.W. Voss, Jr., Partial elucidation of an anti-hapten repertoire in BALB/c mice: comparative characterization of several monoclonal anti-fluorescyl antibodies. Mol Immunol, 1981. 18(10): p. 889-98.

23. Yang, R., et al., IL-12+IL-18 Cosignaling in Human Macrophages and Lung Epithelial Cells Activates Cathelicidin and Autophagy, Inhibiting Intracellular Mycobacterial Growth. J Immunol, 2018. 200(7): p. 2405-2417. 
24. Yang, R., et al., IL-12 Expands and Differentiates Human Vgamma2Vdelta2 T Effector Cells Producing Antimicrobial Cytokines and Inhibiting Intracellular Mycobacterial Growth. Front Immunol, 2019. 10: p. 913.

25. Yu, S., et al., A novel asymmetrical anti-HER2/CD3 bispecific antibody exhibits potent cytotoxicity for HER2-positive tumor cells. J Exp Clin Cancer Res, 2019. 38(1): p. 355.

26. Yang, E., et al., Multidrug-resistant tuberculosis (MDR-TB) strain infection in macaques results in high bacilli burdens in airways, driving broad innate/adaptive immune responses. Emerg Microbes Infect, 2018. 7(1): p. 207.

27. Fan, L., et al., Impairment of Wnt/beta-catenin signaling in blood cells of patients with severe cavitary pulmonary tuberculosis. PLoS One, 2017. 12(3): p. e0172549.

28. Zhang, J., J. Yi, and P. Zhou, Development of bispecific antibodies in China: overview and prospects. Antibody Therapeutics, 2020. 3(2): p. 126-145.

29. Alter, G., J.M. Malenfant, and M. Altfeld, CD107a as a functional marker for the identification of natural killer cell activity. J Immunol Methods, 2004. 294(1-2): p. 15-22.

30. Hoeres, T., et al., PD-1 signaling modulates interferon-gamma production by Gamma Delta (gammadelta) T-Cells in response to leukemia. Oncoimmunology, 2019. 8(3): p. 1550618.

31. Silva-Santos, B., S. Mensurado, and S.B. Coffelt, gammadelta T cells: pleiotropic immune effectors with therapeutic potential in cancer. Nat Rev Cancer, 2019. 19(7): p. 392-404.

32. Chen, Q., T. Li, and W. Yue, Drug response to PD-1/PD-L1 blockade: based on biomarkers. Onco Targets Ther, 2018. 11: p. 4673-4683.

33. Oberg, H.H., et al., $\gamma \delta T$ cell activation by bispecific antibodies. Cell Immunol, 2015. 296(1): p. 41-9.

34. Pauza, C.D., et al., Gamma Delta T Cell Therapy for Cancer: It Is Good to be Local. Front Immunol, 2018. 9: p. 1305.

35. Kabelitz, D., et al., Characterization of tumor reactivity of human $\mathrm{V}$ gamma $9 \mathrm{~V}$ delta 2 gamma delta $T$ cells in vitro and in SCID mice in vivo. J Immunol, 2004. 173(11): p. 6767-76.

36. Silva-Santos, B., K. Serre, and H. Norell, gammadelta T cells in cancer. Nat Rev Immunol, 2015. 15(11): p. 683-91.

37. Hoeres, T., et al., Improving the Efficiency of Vgamma9Vdelta2 T-Cell Immunotherapy in Cancer. Front Immunol, 2018. 9: p. 800.

38. Sebestyen, Z., et al., Translating gammadelta (gammadelta) T cells and their receptors into cancer cell therapies. Nat Rev Drug Discov, 2020. 19(3): p. 169-184.

39. Lo Presti, E., F. Dieli, and S. Meraviglia, Tumor-Infiltrating gammadelta T Lymphocytes: Pathogenic Role, Clinical Significance, and Differential Programing in the Tumor Microenvironment. Front Immunol, 2014. 5: p. 607.

40. Mandikian, D., et al., Relative Target Affinities of T-Cell-Dependent Bispecific Antibodies Determine Biodistribution in a Solid Tumor Mouse Model. Mol Cancer Ther, 2018. 17(4): p. 776-785. 
41. List, T. and D. Neri, Biodistribution studies with tumor-targeting bispecific antibodies reveal selective accumulation at the tumor site. MAbs, 2012. 4(6): p. 775-83.

42. Bortoletto, N., et al., Optimizing anti-CD3 affinity for effective $T$ cell targeting against tumor cells. Eur J Immunol, 2002. 32(11): p. 3102-7.

43. Alarcon, B., et al., The T-cell receptor gamma chain-CD3 complex: implication in the cytotoxic activity of a CD3+ CD4-CD8- human natural killer clone. Proc Natl Acad Sci U S A, 1987. 84(11): p. 3861-5.

44. Dopfer, E.P., et al., The CD3 conformational change in the gammadelta $T$ cell receptor is not triggered by antigens but can be enforced to enhance tumor killing. Cell Rep, 2014. 7(5): p. 1704-1715.

45. Vantourout, P. and A. Hayday, Six-of-the-best: unique contributions of gammadelta $T$ cells to immunology. Nat Rev Immunol, 2013. 13(2): p. 88-100.

\section{Figures}

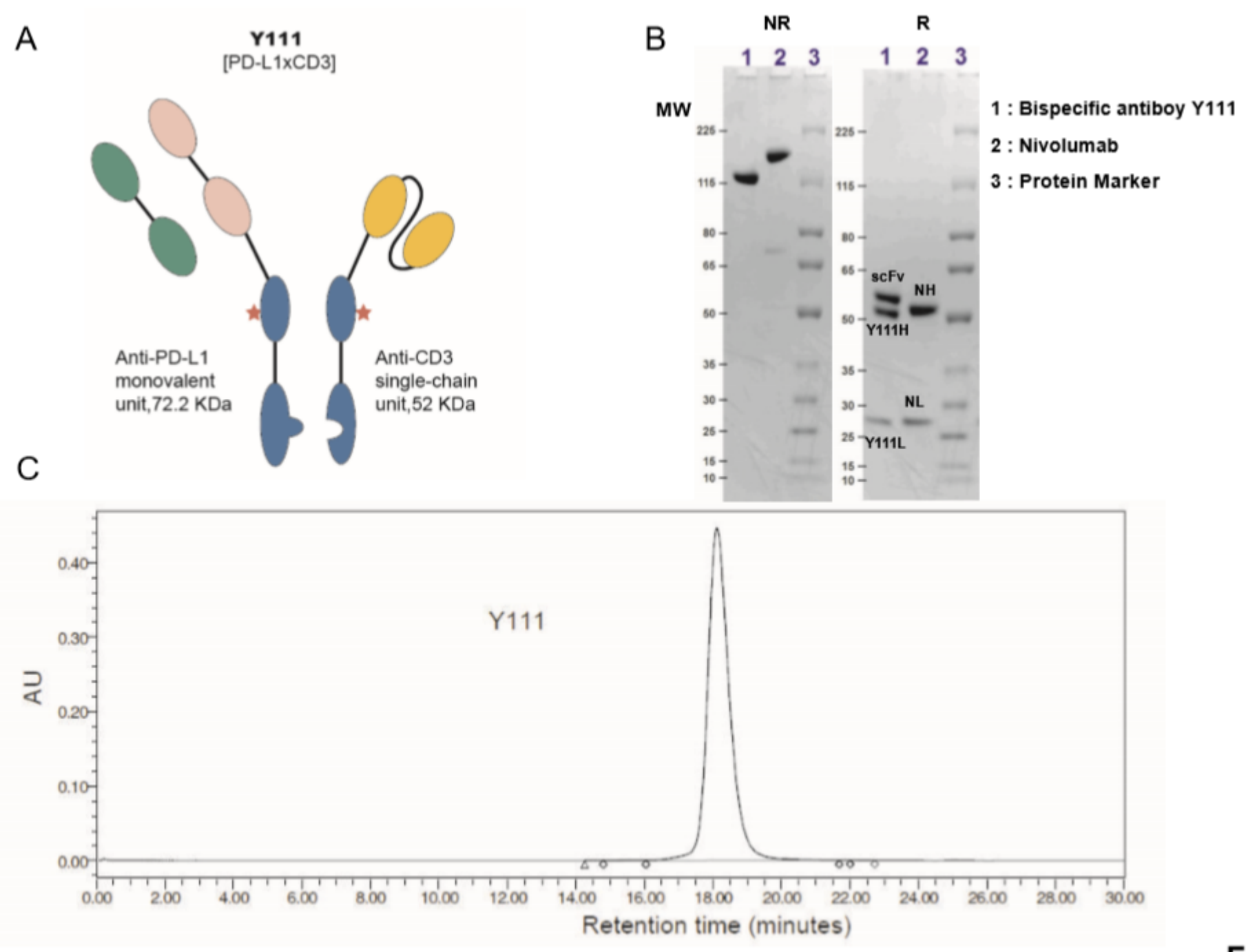

Fig.1

\section{Figure 1}


Generation and purification of Y111, a bispecific antibody targeting both CD3 and PD-L1. (A) Schematic diagram of bispecific antibody $\mathrm{Y} 111$, which consists of a monovalent unit adapted from Atezolizumab, an antibody targeting to PD-L1, and a single chain variable fragment (scFv) from 2A5, an antibody for CD3 activation. The red asterisk indicates N297Q mutation for precluding Fc receptor-mediated crosslinking. A "Knob-into-hole" structure was introduced for purification. (B) SDS-PAGE analysis of purified $\mathrm{Y} 111$ under non-reducing (NR, left) and reducing (R, right) conditions. Nivolumab is a monoclonal antibody utilized as control. Molecular weight (MW) is indicated in KDa for protein marker. The MW of Y111 is a littler smaller than monoclonal antibody Nivolumab as indicated from NR gel. There are 3 and 2 bands for Y111 and Nivolumab in reducing gel respectively as expected. Please note that the nominal MW of $\mathrm{Y} 111 \mathrm{H}$ is $48.850 \mathrm{KDa}, \mathrm{Y} 111 \mathrm{~L}$ is $23.365 \mathrm{KDa}$, scFv is $52.057 \mathrm{KDa}$, and intact $\mathrm{Y} 111$ is $124.272 \mathrm{KDa}$ as predicted by their protein sequences. While the predicted nominal MW of Nivolumab is $143.597 \mathrm{KDa}$, the predicted MW of heavy $(\mathrm{NH})$ and light $(\mathrm{NL})$ chain of Nivolumab is $48.422 \mathrm{KDa}$ and 23.359 KDa, respectively. (C) Size exclusion chromatograms of $\mathrm{Y} 111$ purified by Protein-A and ion-exchange chromatography. The purity for this sample is $99.63 \%$.

A

A

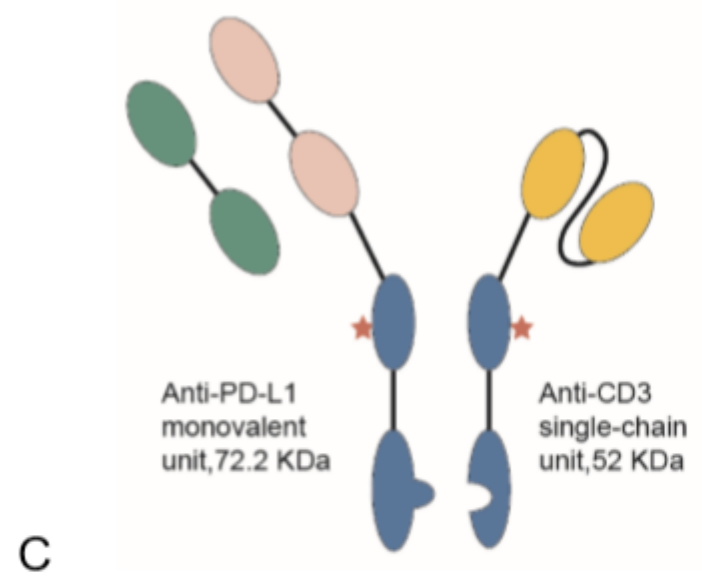

B

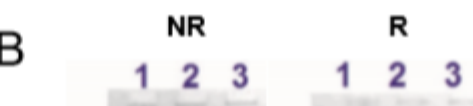

MW

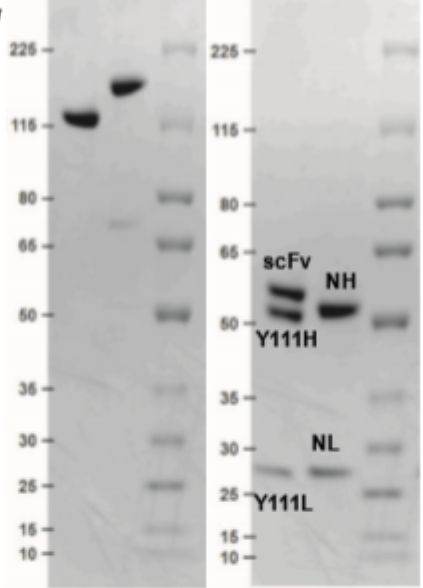

1 : Bispecific antiboy $\mathrm{Y} 111$

2 : Nivolumab

3 : Protein Marker

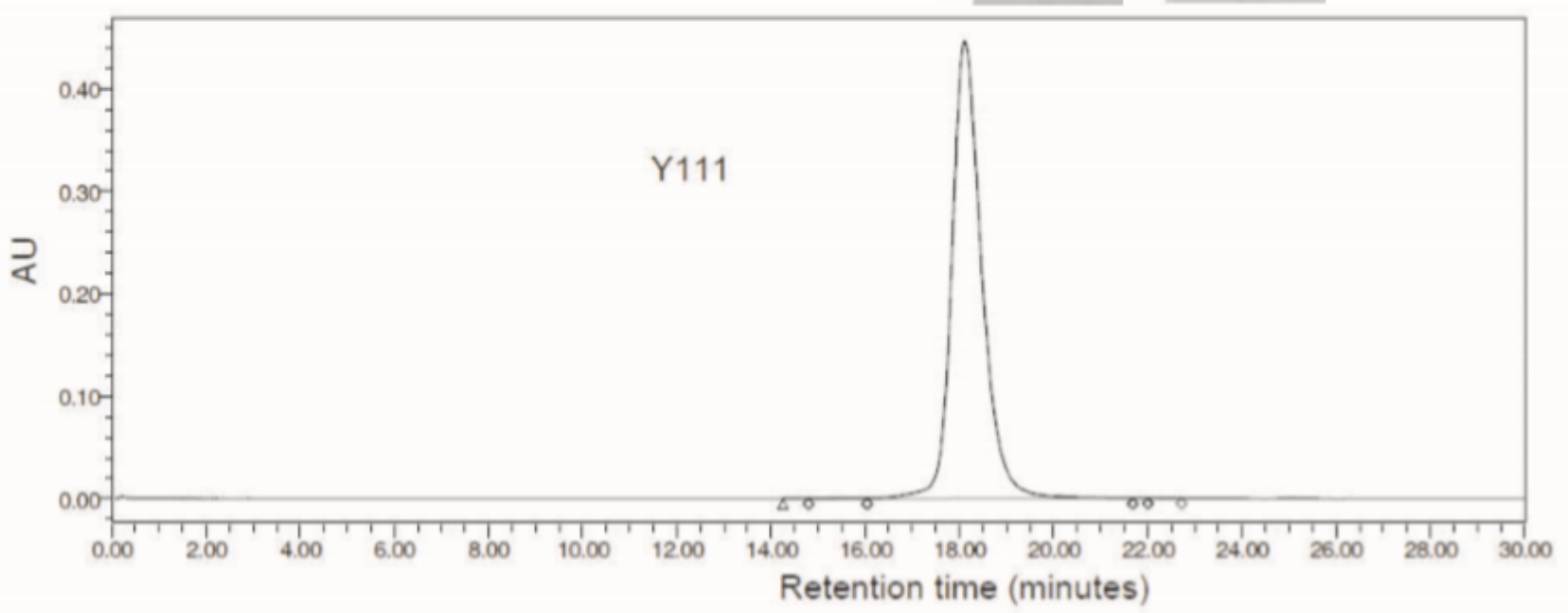

Fig.1

Figure 1 
Generation and purification of Y111, a bispecific antibody targeting both CD3 and PD-L1. (A) Schematic diagram of bispecific antibody $\mathrm{Y} 111$, which consists of a monovalent unit adapted from Atezolizumab, an antibody targeting to PD-L1, and a single chain variable fragment (scFv) from 2A5, an antibody for CD3 activation. The red asterisk indicates N297Q mutation for precluding Fc receptor-mediated crosslinking. A "Knob-into-hole" structure was introduced for purification. (B) SDS-PAGE analysis of purified $\mathrm{Y} 111$ under non-reducing (NR, left) and reducing (R, right) conditions. Nivolumab is a monoclonal antibody utilized as control. Molecular weight (MW) is indicated in KDa for protein marker. The MW of Y111 is a littler smaller than monoclonal antibody Nivolumab as indicated from NR gel. There are 3 and 2 bands for Y111 and Nivolumab in reducing gel respectively as expected. Please note that the nominal MW of $\mathrm{Y} 111 \mathrm{H}$ is $48.850 \mathrm{KDa}, \mathrm{Y} 111 \mathrm{~L}$ is $23.365 \mathrm{KDa}$, scFv is $52.057 \mathrm{KDa}$, and intact $\mathrm{Y} 111$ is $124.272 \mathrm{KDa}$ as predicted by their protein sequences. While the predicted nominal MW of Nivolumab is $143.597 \mathrm{KDa}$, the predicted MW of heavy $(\mathrm{NH})$ and light $(\mathrm{NL})$ chain of Nivolumab is $48.422 \mathrm{KDa}$ and $23.359 \mathrm{KDa}$, respectively. (C) Size exclusion chromatograms of $\mathrm{Y} 111$ purified by Protein-A and ion-exchange chromatography. The purity for this sample is $99.63 \%$.

A

Jurkat

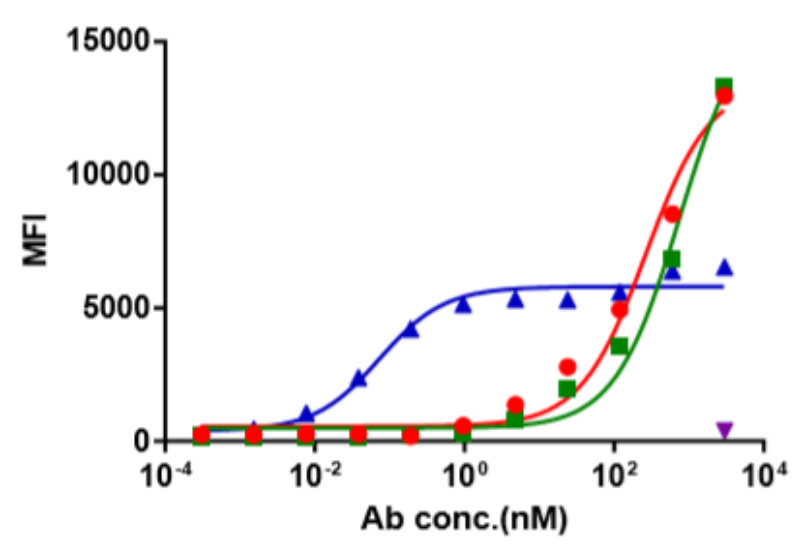

C

$10 \mu \mathrm{g} / \mathrm{mL}$ CD3 Isotype

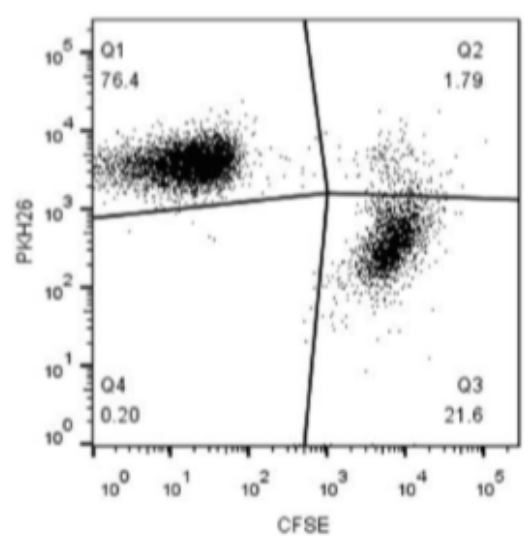

$10 \mu \mathrm{g} / \mathrm{mL} Y 111$

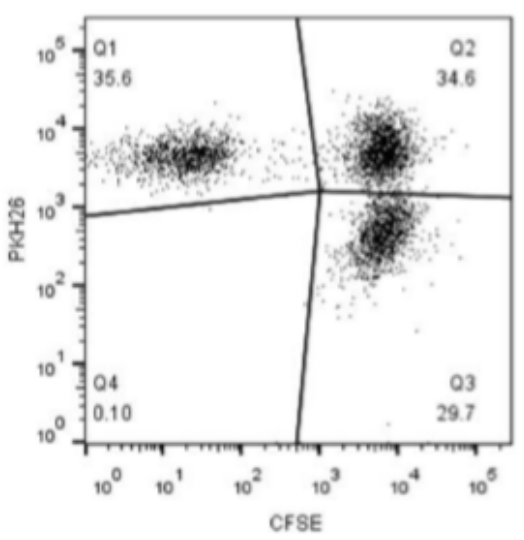

B

H1975

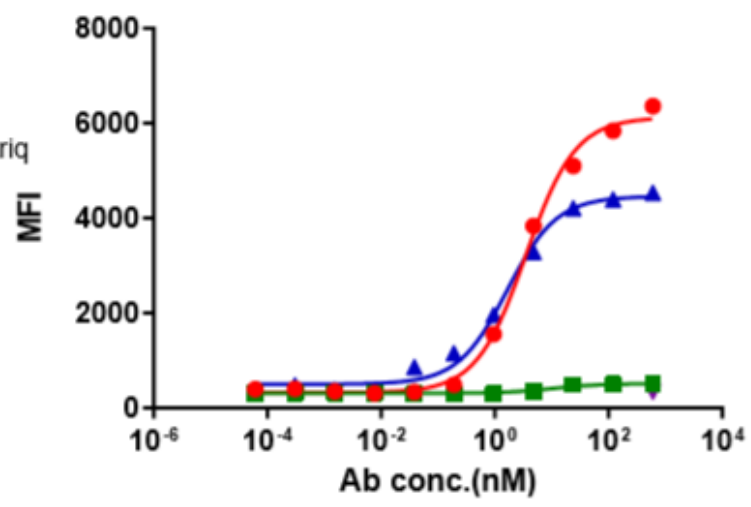

Figure 2

D

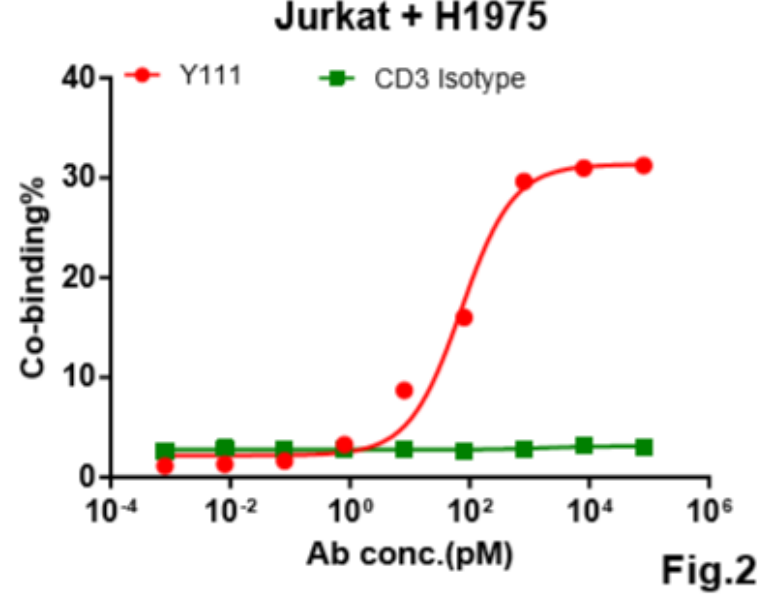


Cell binding activities of $Y 111$. (A-B) The binding affinity of $Y 111$ and control antibodies (concentration range) to the CD3 expressed on Jurkat cells (A), the PD-L1 expressed on the H1975 cells (B). Flow cytometry was used to assess the geometric mean fluorescence (MFI) of PE channel, and data were analyzed using "One Site-Specific binding" method through least squares fitting. Plotted dots were means of triplicate wells in one performed assay, and the shown figures were representative of at least three experiments. (C-D) Y111 bridged the tumor cell and T cells in dose-dependent manner. CFSE-stained H1975 cells were co-cultured with PKH26-labelled Jurkat cells under dose of antibody Y111 or CD3 Isotype for 1 hour. Co-binding\% was indicated as percentages of the CFSE-PKH26-double positive cells (Q2) among cells. Representative co-binding dotplots were shown in C, a nonlinear regression depicting dose dependent-association modulated by $\mathrm{Y} 111$ was shown in D. Data in D were represented as means pooled from four experiments, and were analyzed using "log (agonist) vs. response (three parameters)" method through ordinary fitting.

A

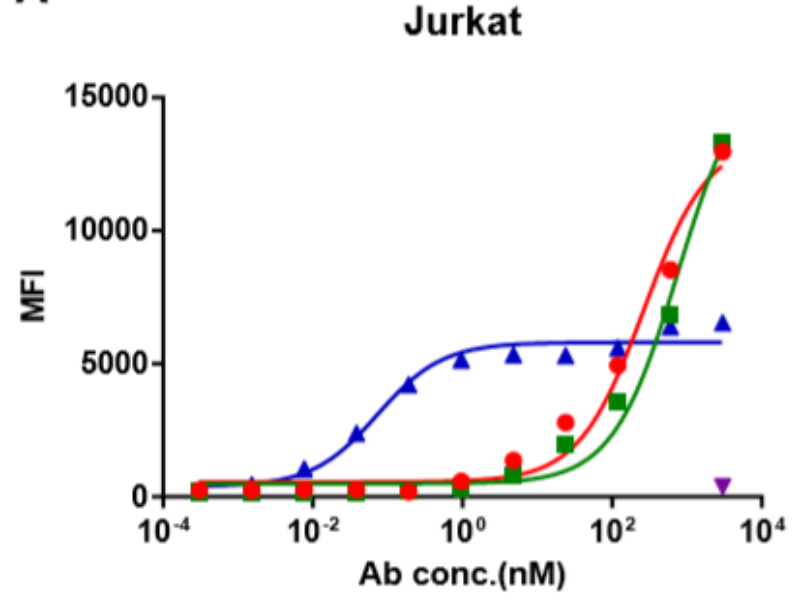

B

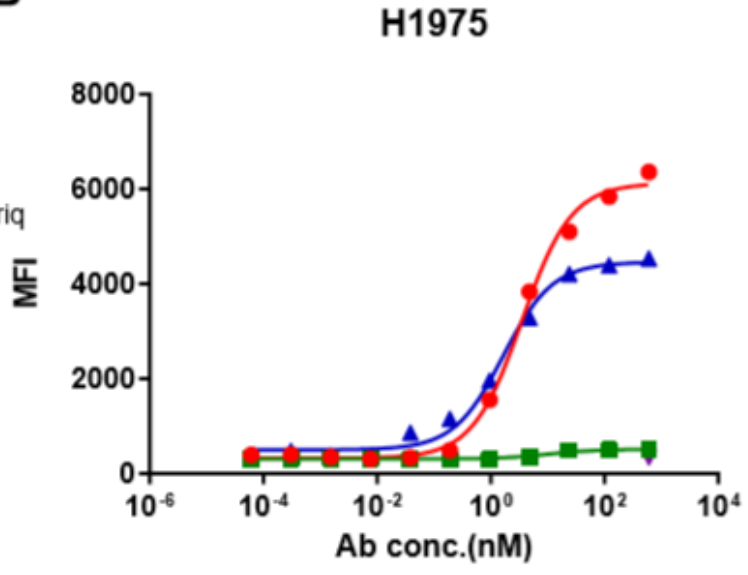

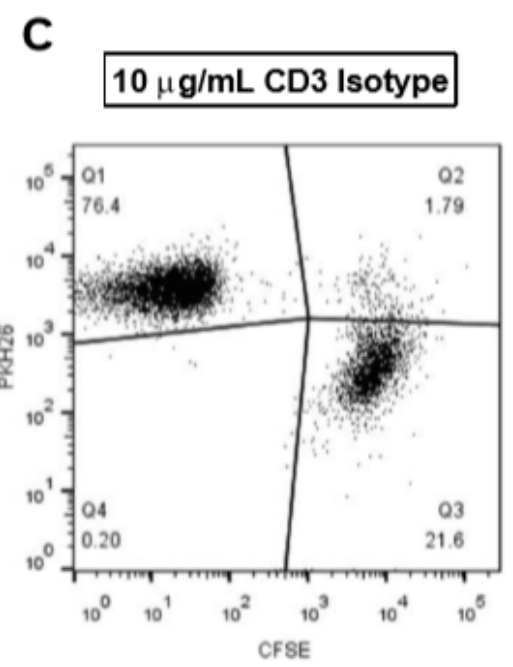

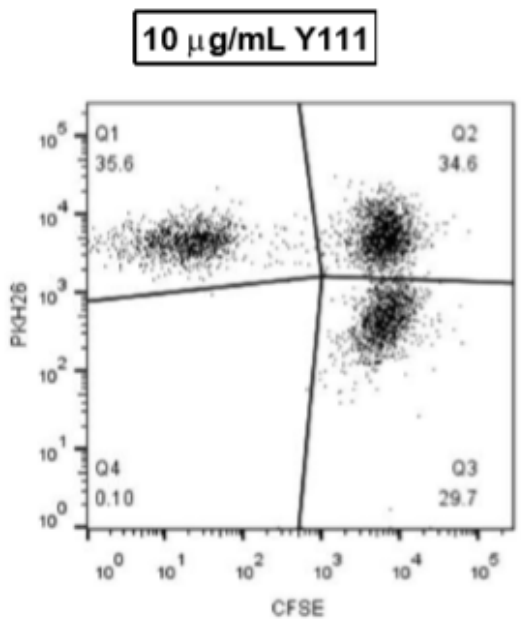

D

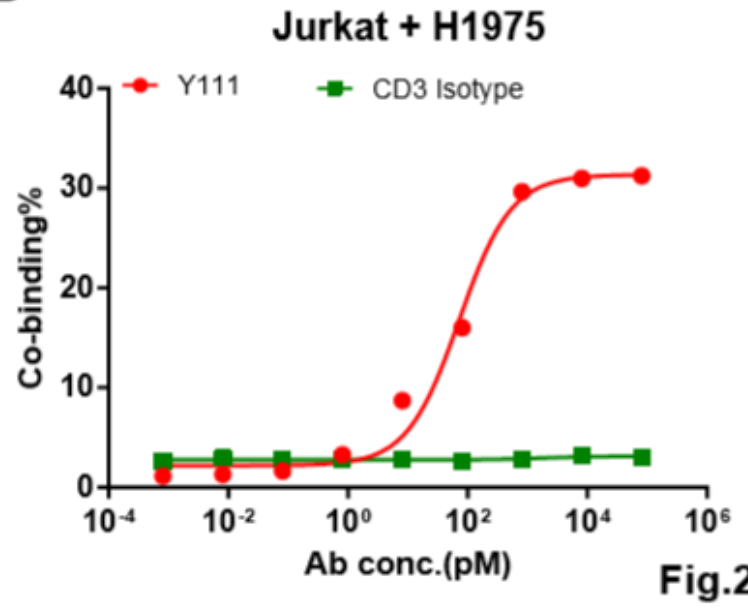

Figure 2

Cell binding activities of $\mathrm{Y} 111$. (A-B) The binding affinity of $\mathrm{Y} 111$ and control antibodies (concentration range) to the CD3 expressed on Jurkat cells (A), the PD-L1 expressed on the H1975 cells (B). Flow cytometry was used to assess the geometric mean fluorescence (MFI) of PE channel, and data were 
analyzed using "One Site-Specific binding" method through least squares fitting. Plotted dots were means of triplicate wells in one performed assay, and the shown figures were representative of at least three experiments. (C-D) Y111 bridged the tumor cell and T cells in dose-dependent manner. CFSE-stained H1975 cells were co-cultured with PKH26-labelled Jurkat cells under dose of antibody Y111 or CD3 Isotype for 1 hour. Co-binding\% was indicated as percentages of the CFSE-PKH26-double positive cells (Q2) among cells. Representative co-binding dotplots were shown in C, a nonlinear regression depicting dose dependent-association modulated by $\mathrm{Y} 111$ was shown in D. Data in D were represented as means pooled from four experiments, and were analyzed using "log (agonist) vs. response (three parameters)" method through ordinary fitting.

A

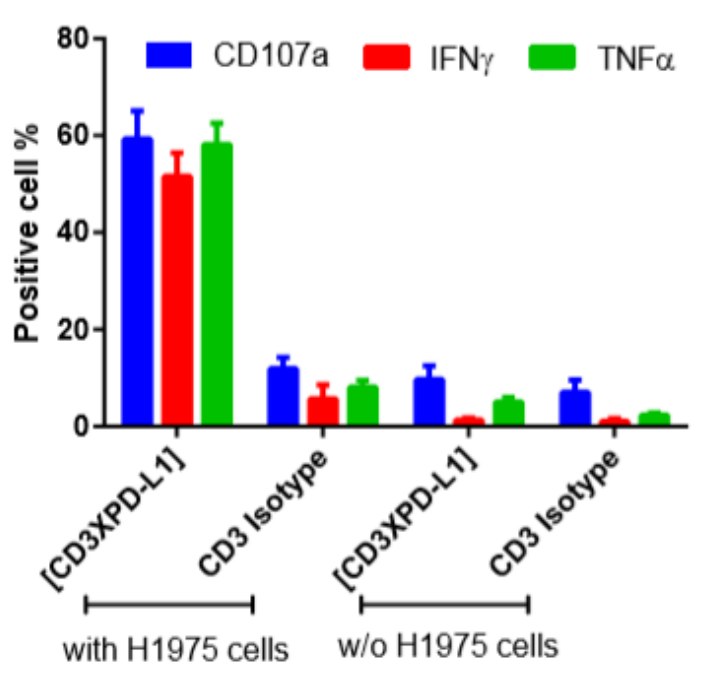

B
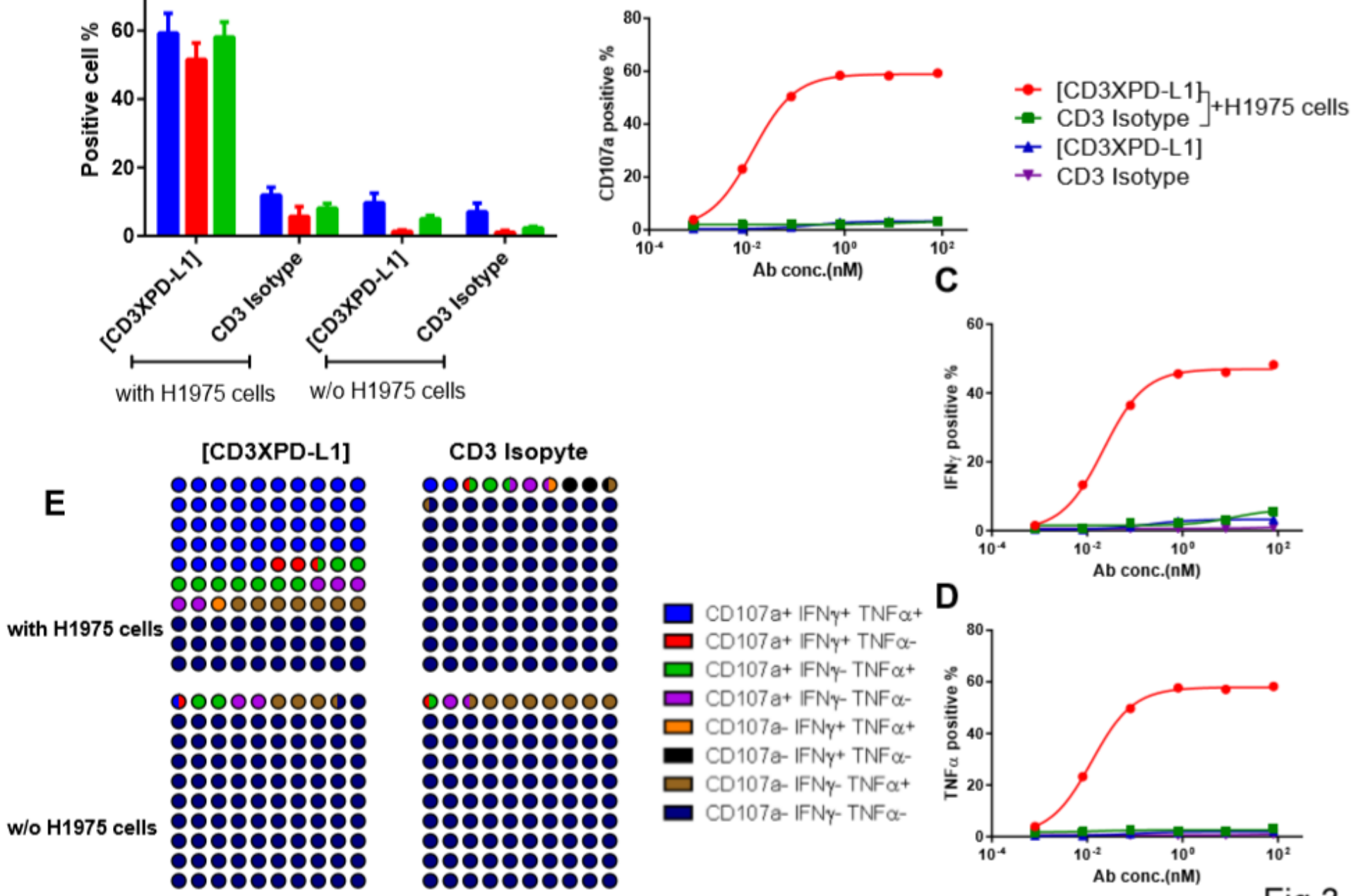

Fig.3

Figure 3

Y111 selectively triggered the cytokine production and degranulation of VY2Vס2 T cells in the presence of target tumor cells. (A-D) Y111 efficiently enhanced the activation of VY2Vס2 T cells to produce IFNY, $\mathrm{TNFa}$, and degranulation in tumor cell-dependent fashion. Vy2Vס2 T cells were stimulated by $\mathrm{Y} 111$ or CD3 Isotype (1 $\mathrm{gg} / \mathrm{mL}$ of each) in (A), and indicated concentration ranges in (B-D) in the presence/absence of $\mathrm{H} 1975$ cells in a 1:1 ratio for 6 hours. The Y111-inuced anti-tumor effector function 
was assessed by determining the percentages of Vy2Vס2 T cells positive for IFNy, TNFa, and CD107a. Bar graph data shown in A were represented as means \pm SEM pooled from three experiments involving with 9 healthy donors, dots in B-D were means of these individual donors. The data in B were analyzed using "log (agonist) vs. response (three parameters)" method through ordinary fitting. (E) Part of whole graph shown the co-expression signatures of VY2Vס2 T cells treated by Y111 or CD3 Isotype (1 $\mu \mathrm{g} / \mathrm{mL}$ of each) in the presence or absence of $\mathrm{H} 1975$ cells. After gating cytokine positive population (Sup.Fig.5), the boolean analysis was utilized to determine the percentages of multi-functional effector subsets of Vy2Vס2 T cells. Data shown were means pooled from 9 healthy donors.

A

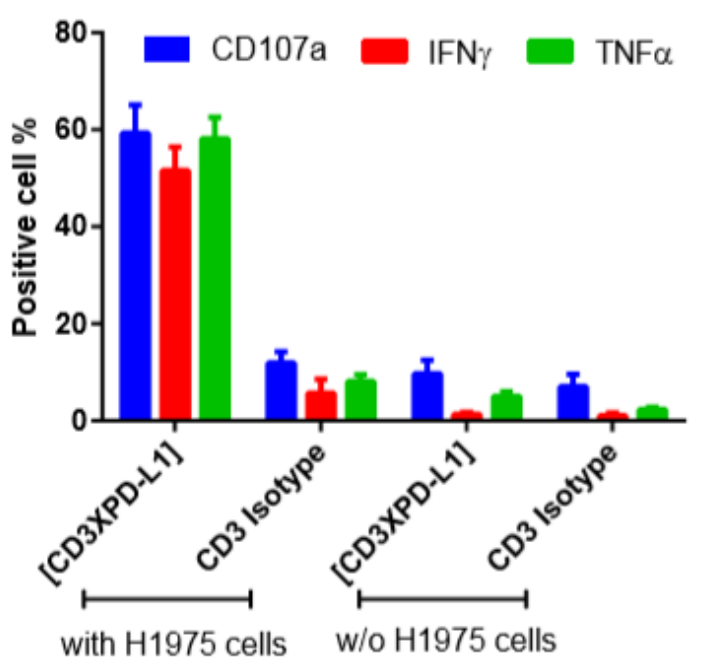

B
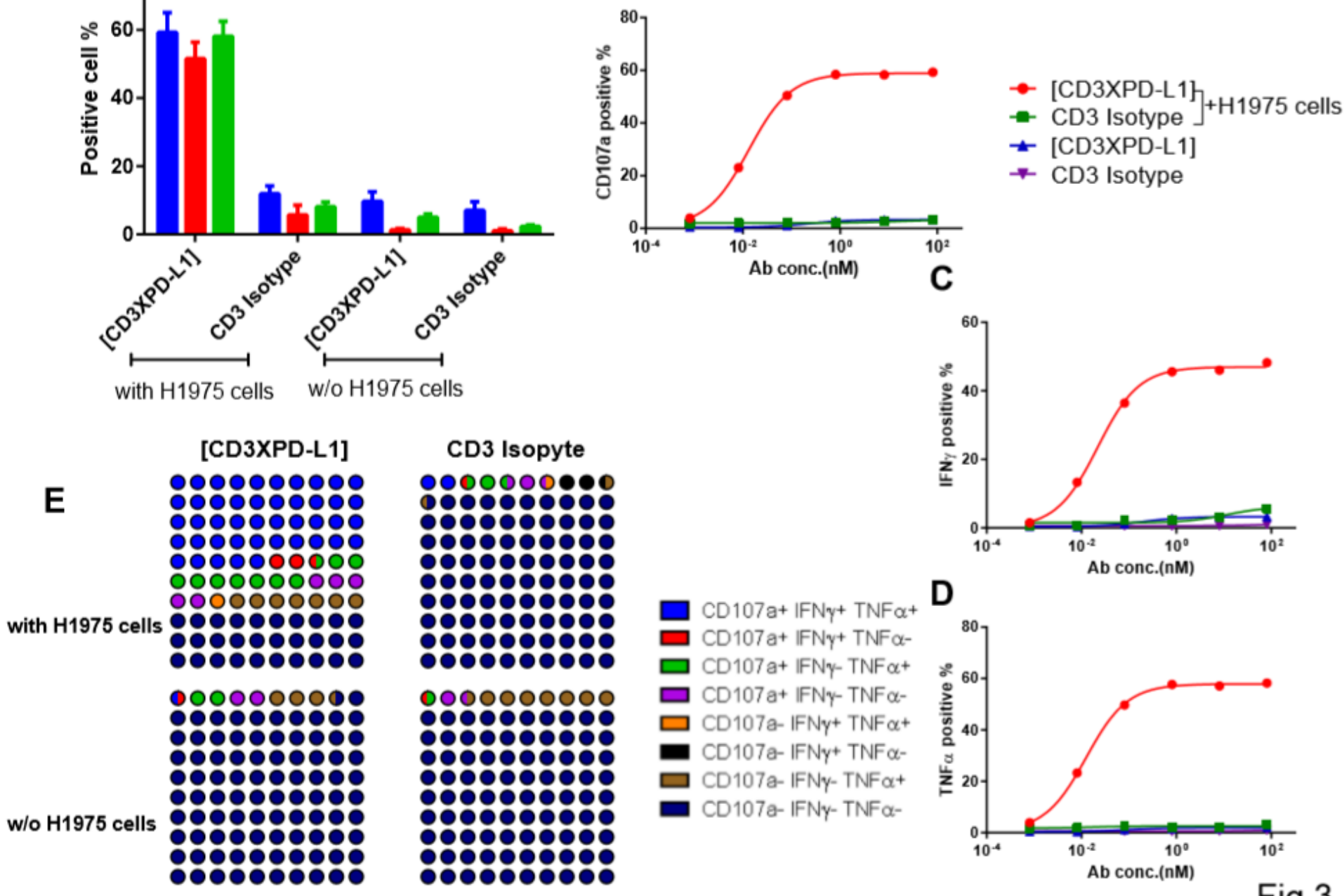

Fig.3

Figure 3

Y111 selectively triggered the cytokine production and degranulation of VY2Vס2 T cells in the presence of target tumor cells. (A-D) Y111 efficiently enhanced the activation of VY2Vס2 T cells to produce IFNY, $\mathrm{TNFa}$, and degranulation in tumor cell-dependent fashion. $\mathrm{V} Y 2 \mathrm{~V} \delta 2 \mathrm{~T}$ cells were stimulated by $\mathrm{Y} 111$ or CD3 Isotype (1 $\mu \mathrm{g} / \mathrm{mL}$ of each) in (A), and indicated concentration ranges in (B-D) in the presence/absence of $\mathrm{H} 1975$ cells in a 1:1 ratio for 6 hours. The Y111-inuced anti-tumor effector function was assessed by determining the percentages of $\mathrm{V} \gamma 2 \mathrm{~V} \delta 2 \mathrm{~T}$ cells positive for IFNy, TNFa, and CD107a. 
Bar graph data shown in A were represented as means \pm SEM pooled from three experiments involving with 9 healthy donors, dots in B-D were means of these individual donors. The data in B were analyzed using "log (agonist) vs. response (three parameters)" method through ordinary fitting. (E) Part of whole graph shown the co-expression signatures of VY2Vס2 T cells treated by Y111 or CD3 Isotype $(1 \mu \mathrm{g} / \mathrm{mL}$ of each) in the presence or absence of $\mathrm{H} 1975$ cells. After gating cytokine positive population (Sup.Fig.5), the boolean analysis was utilized to determine the percentages of multi-functional effector subsets of Vy2Vס2 T cells. Data shown were means pooled from 9 healthy donors.

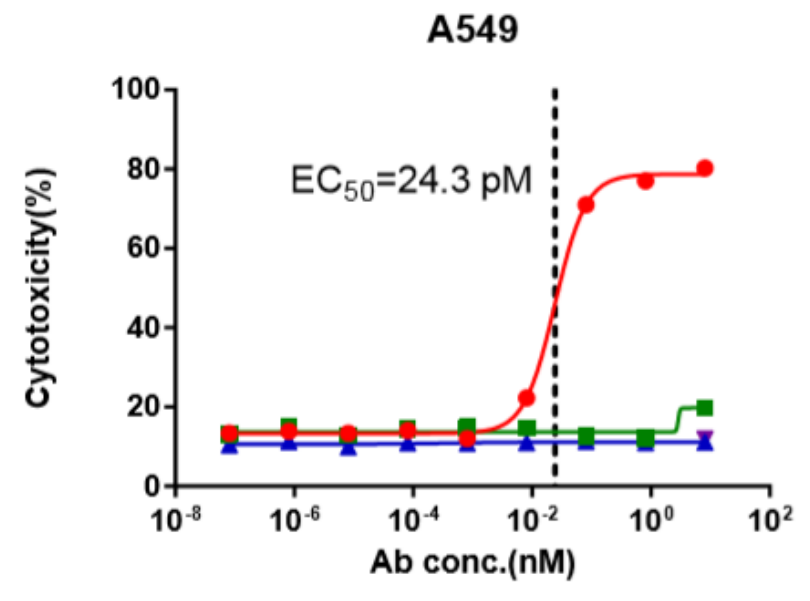

H358

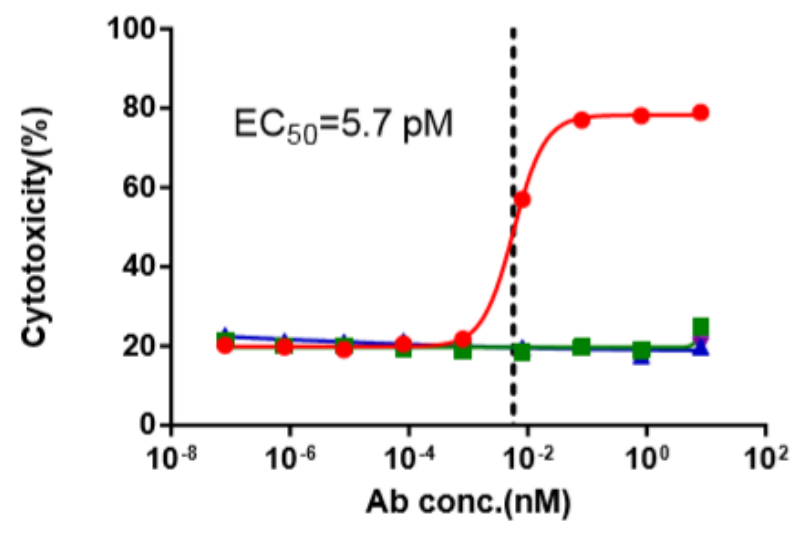

H1299

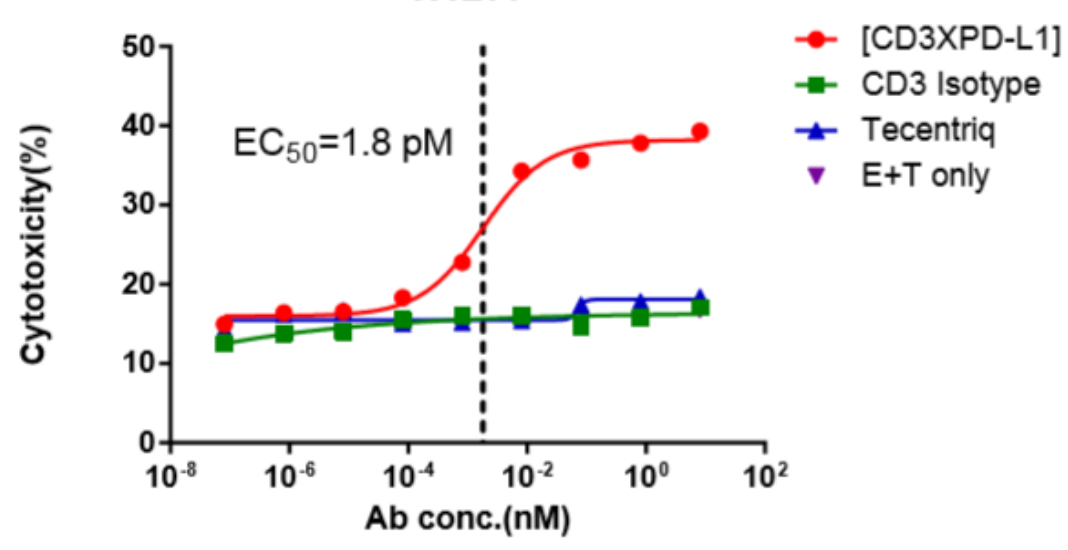

H1975
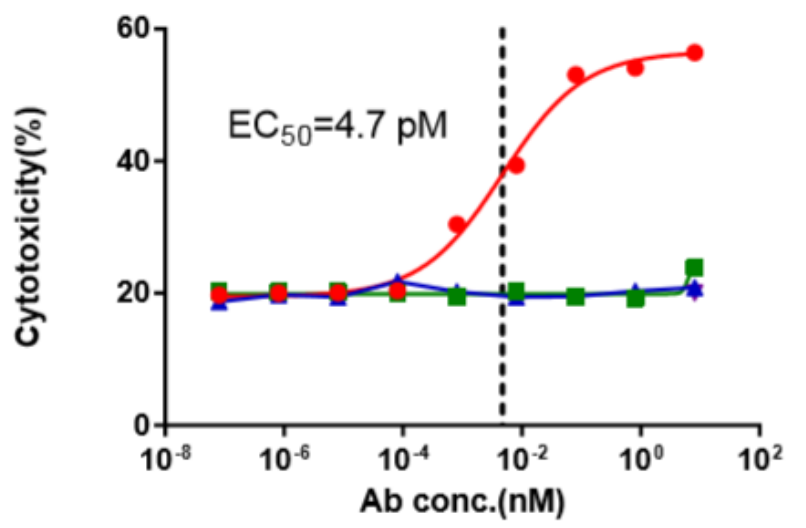

Fig.4

\section{Figure 4}

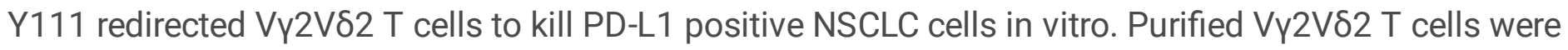
incubated with various NSCLC cell lines, including A549, $\mathrm{H} 1299, \mathrm{H} 1975$, and $\mathrm{H} 358$, in 1:1 ratio under the stimulation of derail dilutions of $\mathrm{Y} 111, \mathrm{CD} 3$ Isotype or Tecentriq for 12 hours, then the proportions of killed target cells were plotted. The cell lines used were PD-L1 positive shown in Sup.Fig.4. Dots shown in figures were represented as means of triplicate wells, and were analyzed using "log (agonist) vs. response- Variable slope (four parameters)" method through ordinary fitting. Then the calculated EC50 values were shown. Experiments were involved with 9 healthy donors, and similar results were obtained. 
A549

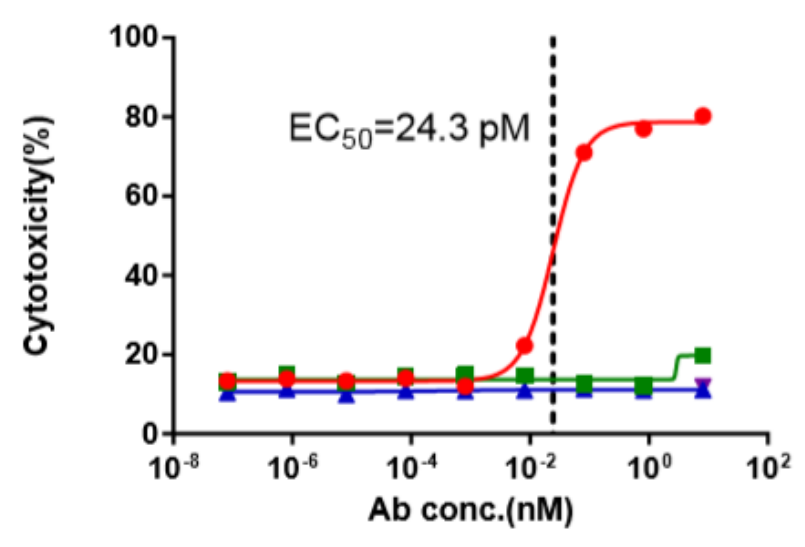

H358

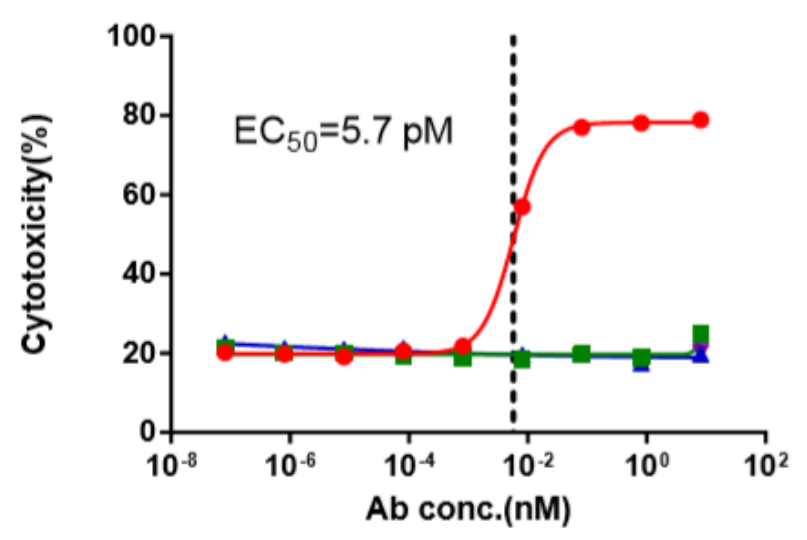

H1299

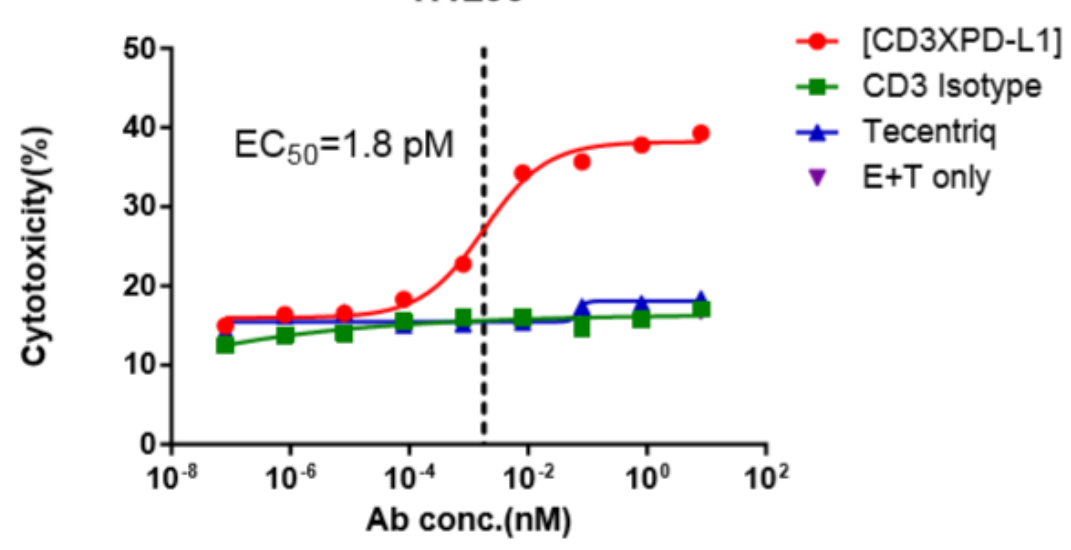

H1975

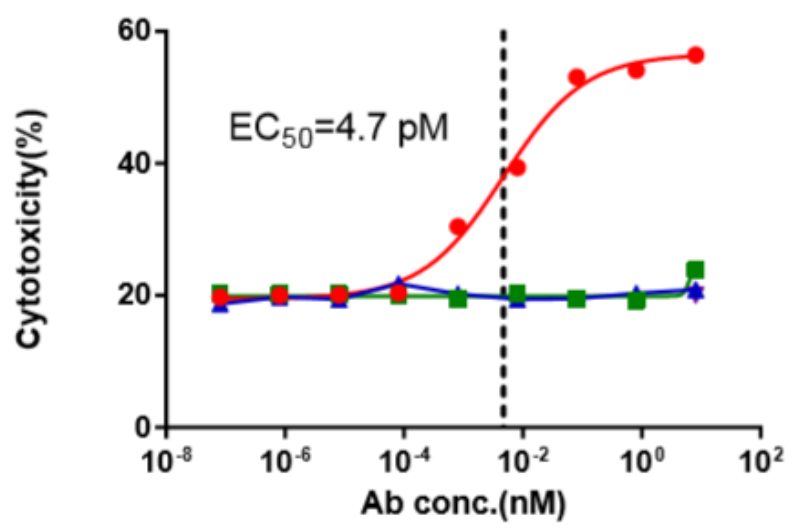

Fig. 4

\section{Figure 4}

Y111 redirected Vy2Vס2 T cells to kill PD-L1 positive NSCLC cells in vitro. Purified VY2Vס2 T cells were incubated with various NSCLC cell lines, including A549, H1299, H1975, and H358, in 1:1 ratio under the stimulation of derail dilutions of Y111, CD3 Isotype or Tecentriq for 12 hours, then the proportions of killed target cells were plotted. The cell lines used were PD-L1 positive shown in Sup.Fig.4. Dots shown in figures were represented as means of triplicate wells, and were analyzed using "log (agonist) vs. response- Variable slope (four parameters)" method through ordinary fitting. Then the calculated EC50 values were shown. Experiments were involved with 9 healthy donors, and similar results were obtained. 

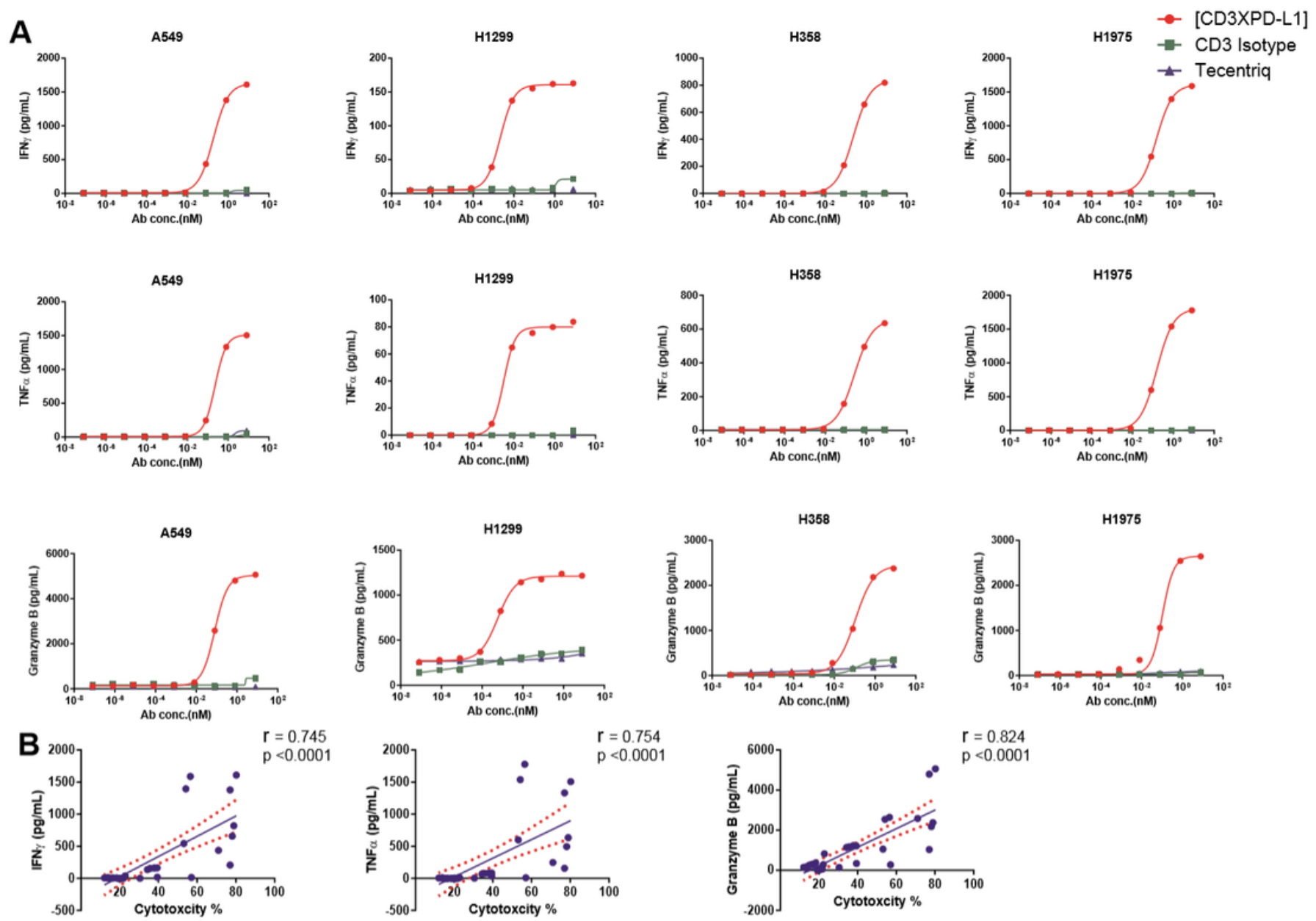

\section{Figure 5}

Vy2Vס2 T cells treated by Y111 secreted IFNy, TNFa and granzyme B. (A) Increased cytokine secretion by VY2V82 $\mathrm{T}$ cells after co-culture for $12 \mathrm{~h}$ with tumor cells plus Y111 or control antibodies (as indicated in Fig.4) analyzed by CBA. Please note that the shown values were the results of raw values subtracted E+T only groups. (B) The enhanced cytotoxicity induced by $\mathrm{Y} 111$ correlated with the increased production of IFNy, TNFa, and granzyme B. The spearman's $r$ and two-tailed $p$ values were calculated by GraphPad prism 6 . The blue line indicated best-fit linear, and red line indicated $95 \%$ confidence band of the best-fit line. Experiments were involved with 9 healthy donors, and a representative result was shown. 

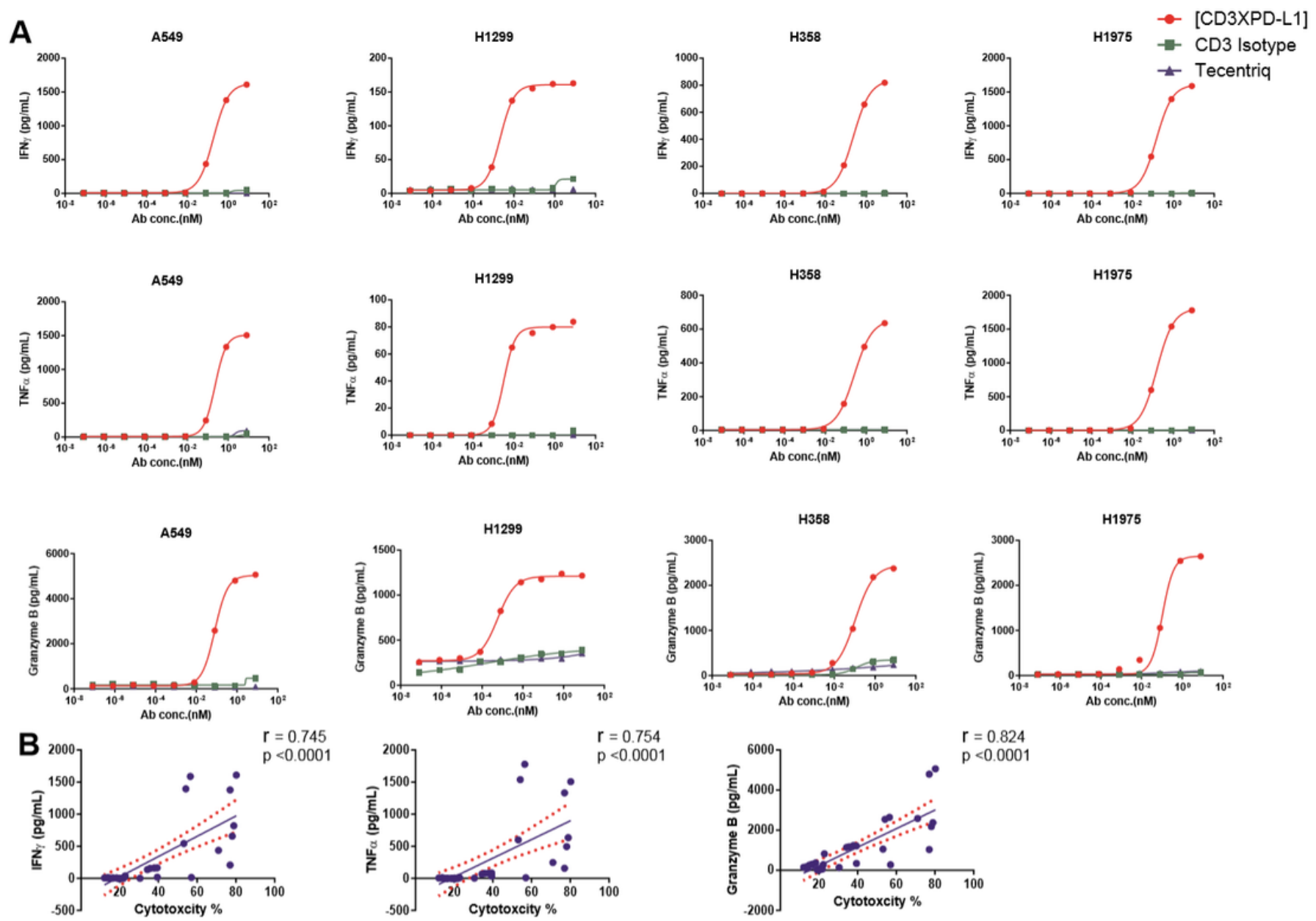

\section{Figure 5}

Vy2Vס2 T cells treated by Y111 secreted IFNy, TNFa and granzyme B. (A) Increased cytokine secretion by VY2V82 $\mathrm{T}$ cells after co-culture for $12 \mathrm{~h}$ with tumor cells plus Y111 or control antibodies (as indicated in Fig.4) analyzed by CBA. Please note that the shown values were the results of raw values subtracted E+T only groups. (B) The enhanced cytotoxicity induced by $\mathrm{Y} 111$ correlated with the increased production of IFNy, TNFa, and granzyme B. The spearman's $r$ and two-tailed $p$ values were calculated by GraphPad prism 6 . The blue line indicated best-fit linear, and red line indicated $95 \%$ confidence band of the best-fit line. Experiments were involved with 9 healthy donors, and a representative result was shown. 


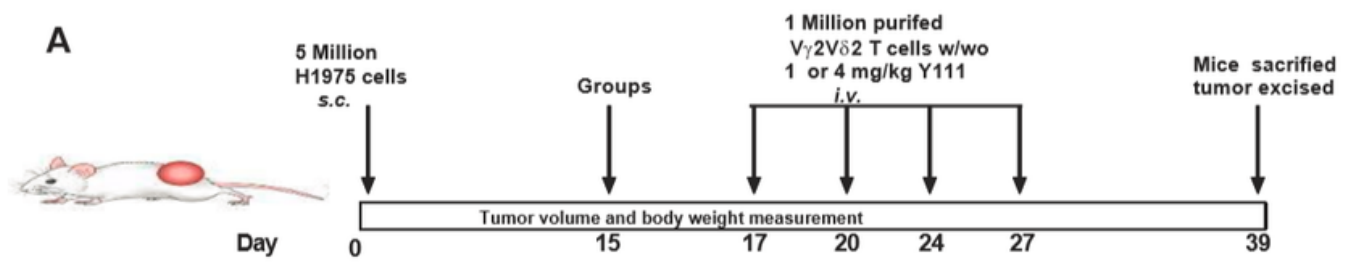

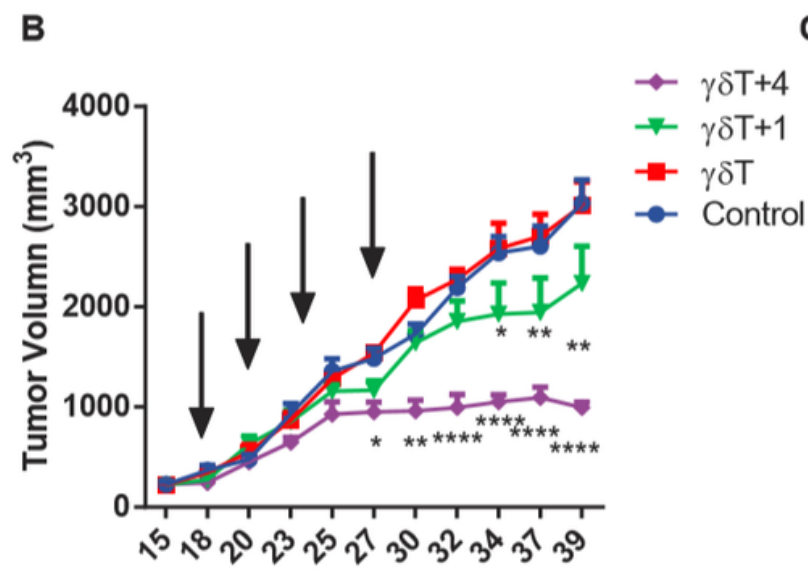

Days after tumor cell inoculation
C

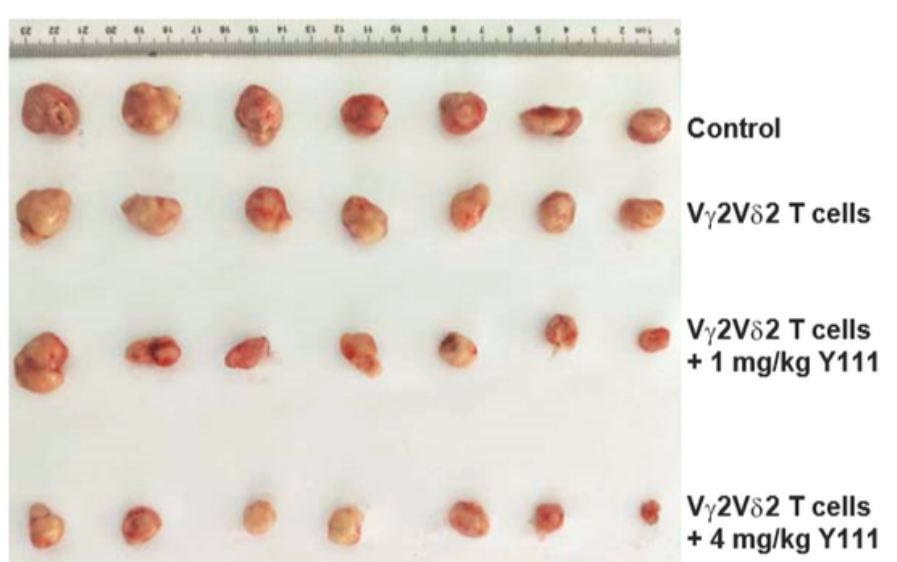

Group2:V $\gamma 2 \mathrm{~V} \delta 2 \mathrm{~T}$ cells

E

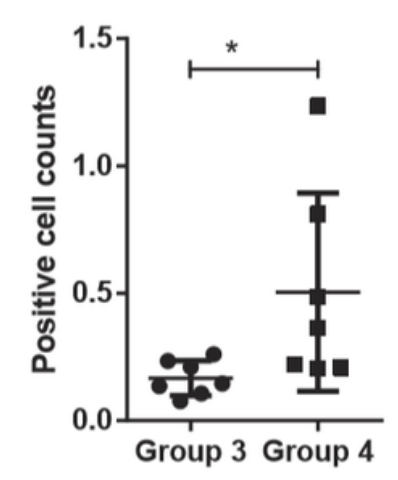

Fig.6

\section{Figure 6}

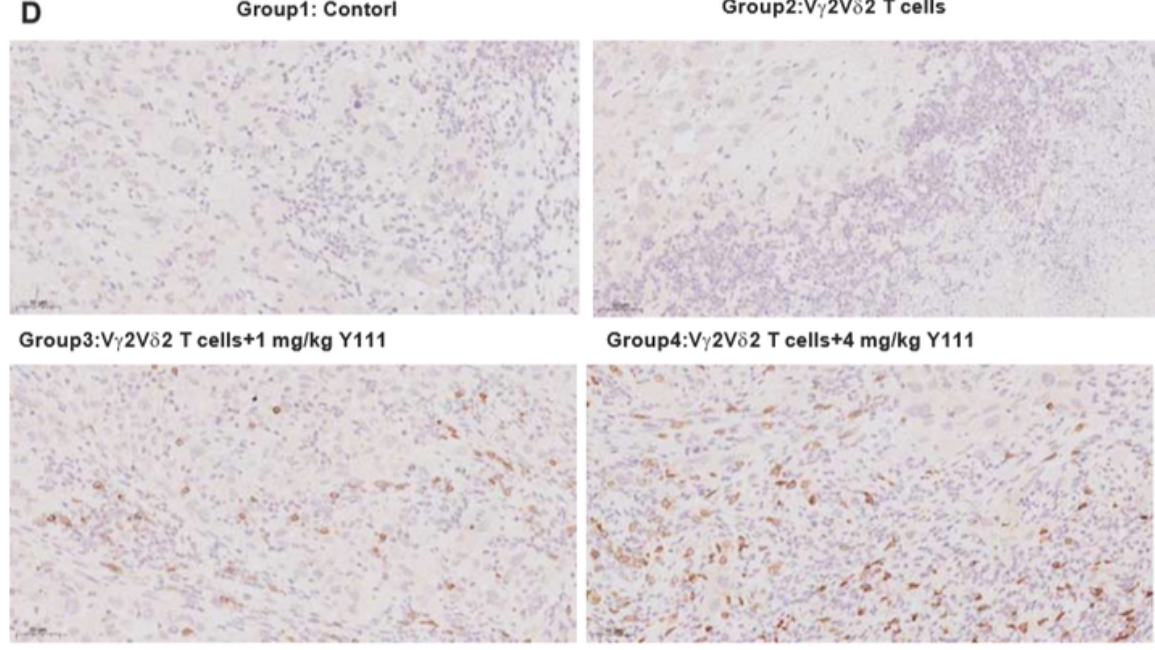

The combination of transfused VY2Vס2 T cells with Y111 significantly inhibited the tumor growth in vivo. (A) Experimental schema of protocols for establishing xenograft in NPG mice and evaluating the antitumor therapeutic efficacy of different treatments. Immunodeficient NPG mice were s.c. inoculated with H1975 NSCLC cells on day 0. After seventeen days, mice were treated with i.v. transfused Vy2Vס2 T cells $\mathrm{w} /$ wo 1 or $4 \mathrm{mg} / \mathrm{kg}$ Y111. These treatments were repeated twice a week for 2 weeks. Mice treated PBS were used as control. (B) Tumor growth curve in NPG mice treated with purified VY2Vס2 T cells w/wo 1 or $4 \mathrm{mg} / \mathrm{kg}$ Y111. Mice received PBS or VY2Vס2 T cells were served as control. The black arrows indicated treatment time point. Data are mean \pm SEM with 7 mice per group, ${ }^{* \star * *} p<0.0001$, ${ }^{* *} p<0.01,{ }^{*} p<0.05$ 
versus control group, two-way ANOVA followed by Dunnett test. (C) Inspection of tumor tissues excised from different groups indicated above on at the end of the study. (D) Representative are shown. IHC photomicrographs of tumors excited from mice stained with anti-human CD3 antibody. Magnification, 20X. (E) Infiltrated and accumulated T-cell counts at the tumor site. Quantitative analysis of VY2Vס2 T cells was done by counting positive dots in a total of 70 fields from 14 mice. We did not find the accumulation of VY2V82 T cells in other two groups. Each dot represented one mouse. Data were presented as mean $\pm \mathrm{SEM},{ }^{*} \mathrm{p}<0.05$, Mann Whitney U test.

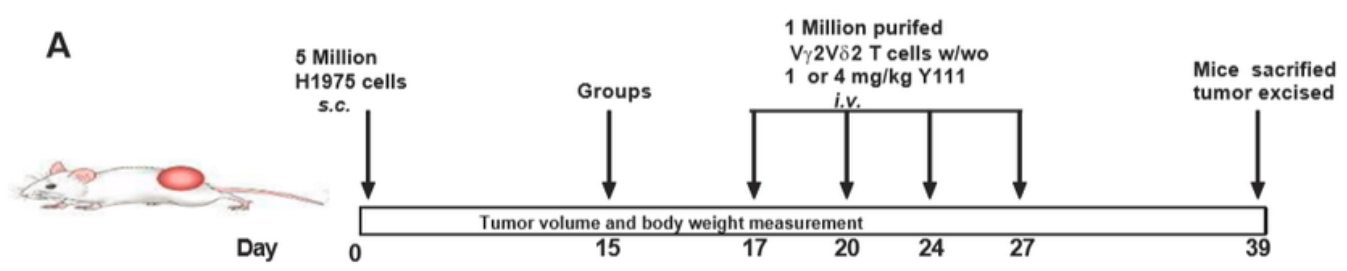

B

C

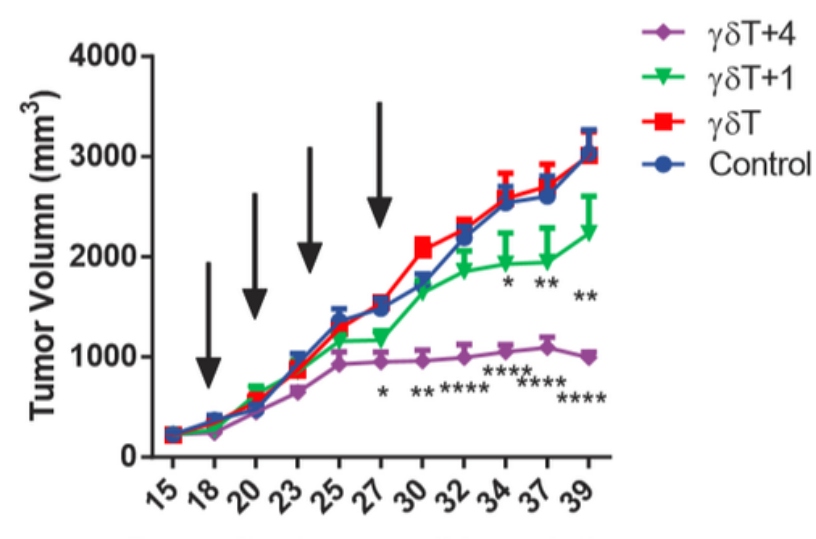

Days after tumor cell inoculation

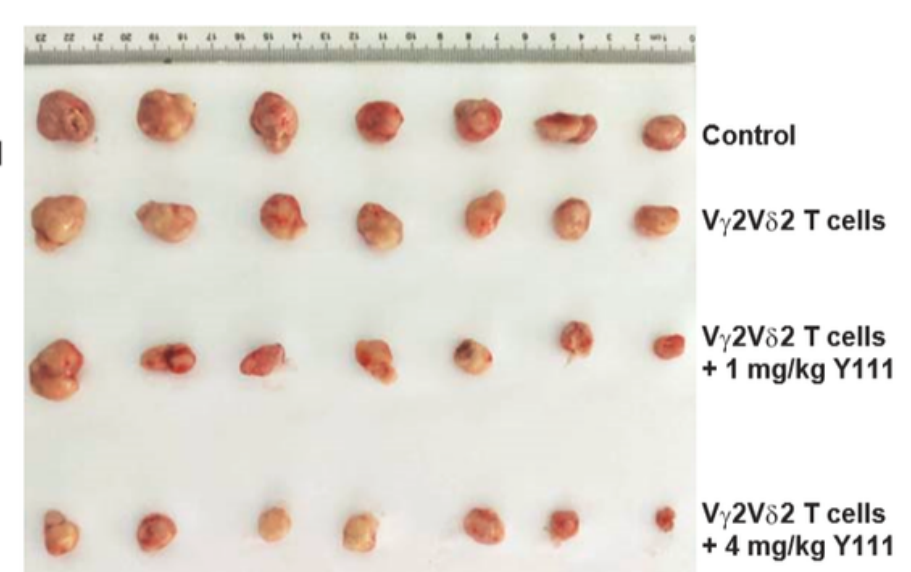

D

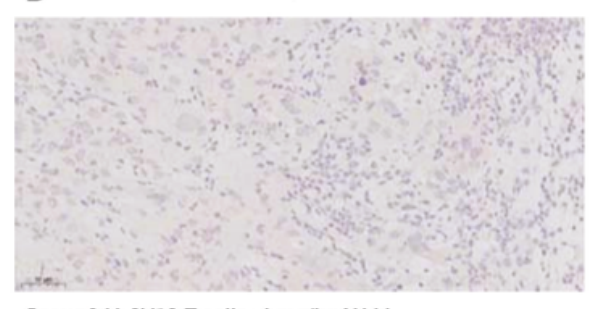

Group3:V $\gamma 2 \mathrm{~V} \delta 2 \mathrm{~T}$ cells $+1 \mathrm{mg} / \mathrm{kg} \mathrm{Y} 111$

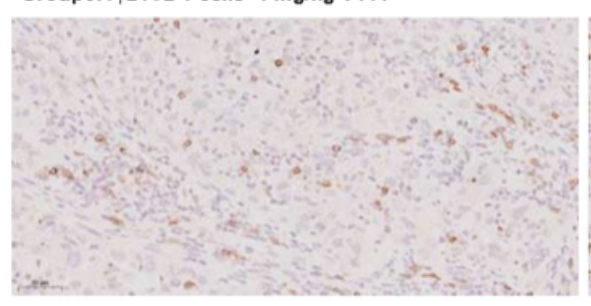

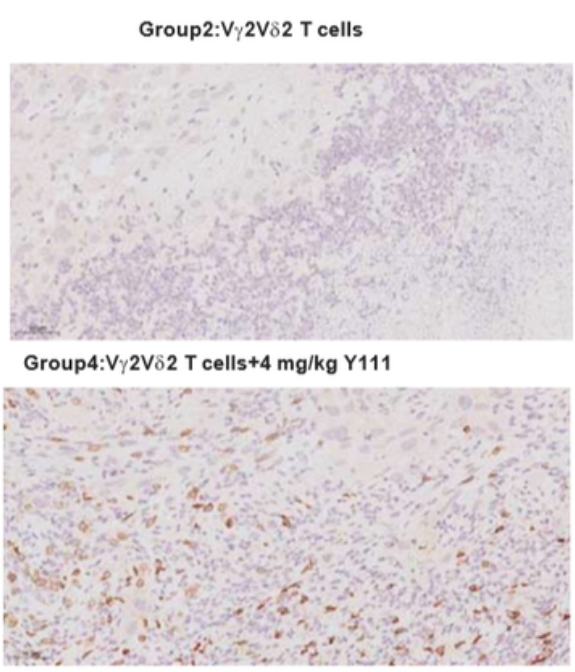

E

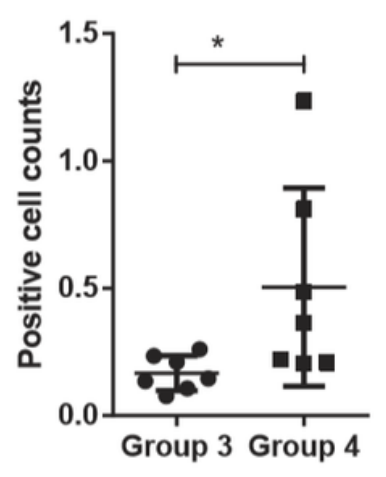

Fig.6

\section{Figure 6}


The combination of transfused VY2Vס2 T cells with Y111 significantly inhibited the tumor growth in vivo. (A) Experimental schema of protocols for establishing xenograft in NPG mice and evaluating the antitumor therapeutic efficacy of different treatments. Immunodeficient NPG mice were s.c. inoculated with H1975 NSCLC cells on day 0. After seventeen days, mice were treated with i.v. transfused VY2Vס2 T cells $\mathrm{w} /$ wo 1 or $4 \mathrm{mg} / \mathrm{kg}$ Y111. These treatments were repeated twice a week for 2 weeks. Mice treated PBS were used as control. (B) Tumor growth curve in NPG mice treated with purified VY2Vס2 T cells w/wo 1 or $4 \mathrm{mg} / \mathrm{kg}$ Y111. Mice received PBS or VY2Vס2 T cells were served as control. The black arrows indicated treatment time point. Data are mean \pm SEM with 7 mice per group, ${ }^{\star \star \star \star} p<0.0001, * \star p<0.01,{ }^{\star} p<0.05$ versus control group, two-way ANOVA followed by Dunnett test. (C) Inspection of tumor tissues excised from different groups indicated above on at the end of the study. (D) Representative are shown. IHC photomicrographs of tumors excited from mice stained with anti-human CD3 antibody. Magnification, 20X. (E) Infiltrated and accumulated T-cell counts at the tumor site. Quantitative analysis of VY2Vס2 T cells was done by counting positive dots in a total of 70 fields from 14 mice. We did not find the accumulation of Vy2Vס2 T cells in other two groups. Each dot represented one mouse. Data were presented as mean $\pm \mathrm{SEM},{ }^{*} \mathrm{p}<0.05$, Mann Whitney $\mathrm{U}$ test.

\section{Supplementary Files}

This is a list of supplementary files associated with this preprint. Click to download.

- Supfig1.pdf

- Supfig1.pdf

- Supfig2.pdf

- Supfig2.pdf

- Supfig3.pdf

- Supfig3.pdf

- Supfig4.pdf

- Supfig4.pdf

- Supfig5.pdf

- Supfig5.pdf

- Supfig6.pdf

- Supfig6.pdf

- Supfig7.pdf

- Supfig7.pdf

- Supfig8.pdf

- Supfig8.pdf 